\title{
"Disciplinarização" e construção institucional da sociologia nos páises fundadores e sua reprodução na América Latina
}

\section{Hélgio Trindade*}

\section{Resumo}

Este artigo propõe-se a fazer um recorte analítico para focar a emergência da sociologia, sua primeira institucionalização nos países fundadores (Europa e Estados Unidos) e sua reprodução na América Latina, integrando o projeto de pesquisa sobre o processo de institucionalização, diversificação disciplinar e intercâmbio acadêmico das ciências sociais no Brasil em perspectiva latino-americana (antropologia, ciência política e sociologia), no período de 1930-2003.

Palavras-chave: Sociologia. Ciências Sociais. Institucionalização. Europa. Estados Unidos. América Latina.

\footnotetext{
* Universidade Federal do Rio Grande do Sul, Brasil.

- O autor agradece a leitura crítica e as contribuições dos colegas Gerónimo de Sierra, José Vicente Tavares dos Santos, Maria Izabel Noll e a criteriosa e competente revisão de Ricardo dos Santos e da bolsista de iniciação científica, Kézya da Rosa Ferrari.
} 


\section{"Disciplinarization" and institutionalization of sociology in the founding countries and its reproduction in Latin America}

\section{Abstract}

This article offers an analytical framework on the emergence of sociology, and its institutionalization in the founding countries (Europe and the United States) and reproduction in Latin America. It focuses on the development of a research project on the process of institutionalization, disciplinary diversification and academic exchange of social sciences (Anthropology, Political Science and Sociology) in Brazil, seen through a Latin American perspective, in the period of 1930-2003.

Keywords: Sociology. Social Sciences. Institutionalization. Europa. United States. Latin America.

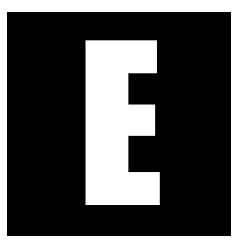

ste artigo propõe-se a analisar as origens da sociologia na Europa e nos Estados Unidos e sua reprodução na América Latina e integra o projeto de pesquisa As ciências sociais no Brasil em perspectiva latino-americana ${ }^{1}$. A partir de 2004, ampliou-se o campo da pesquisa para além do Brasil, incluindo entrevistas com cientistas sociais de outros países da América Latina². Com o apoio financeiro do Institut d'Études Avancées (IEA) e da Maison des Sciences de l'Homme (MSH/Paris), o projeto associou um grupo de pesquisadores-sêniores de Argentina, Brasil, Chile, México e Uruguai (Trindade, 2004; 2005; 2006; 2007; 2012; 2013). Neste campo de pesquisa, cabe destacar a contribuição pioneira de Sérgio Miceli (1989), com a colaboração de um importante grupo de cientistas sociais de São Paulo e do Rio de Janeiro. Em termos latino-americanos, a referência mais importante é a obra coordenada por Carlos Altamirano (2010).

\footnotetext{
${ }^{1}$ Este projeto de pesquisa começou a ser desenvolvido entre 2000 e 2002, tendo como foco o Brasil, em cooperação acadêmica com a École des Hautes Études en Sciences Sociales (EHESS/ Paris), da qual o autor foi pesquisador-visitante e contou com o apoio do Centre de Recherches sur le Brésil Contemporain.

${ }^{2} \mathrm{O}$ banco de entrevistas (com 576 cientistas sociais brasileiros e 131 de outros países da América Latina) reúne um acervo de depoimentos semidiretivos gravados pelo autor, com antropólogos, cientistas políticos e sociólogos.
} 


\section{A invenção da sociologia nos países fundadores}

Para melhor compreender as condições históricas da importação da sociologia na América Latina, como prática social e acadêmica, seria instigante recuperar seu complexo processo na Europa e nos Estados Unidos ${ }^{3}$. Essa incursão às origens da sociologia não tem como foco a análise das obras clássicas dos seus precursores, mas se circunscreve à dinâmica da "disciplinarização" ${ }^{4}$ da sociologia e sua difícil inserção institucional. Após longa e diversificada passagem da militância, social ou política, associada às transformações das referidas sociedades, a sociologia emergente ingressou, com muitas resistências, na academia. A problemática central do artigo busca responder a uma questão prévia: até que ponto o padrão de emergência e implantação da sociologia, observada nos países centrais, reconfigurou sua reprodução latino-americana ou se houve caminhos próprios nas experiências nacionais e no papel de instituições transnacionais?

\subsection{A conflitiva emergência da sociologia na Alemanha, França e Inglaterra}

Convém, desde logo, referir que, em suas origens na Europa Ocidental, associadas à lenta irrupção da sociologia na segunda metade do século XIX, ocorreram significativas mudanças no campo intelectual, num período ainda marcado pela herança da Revolução Francesa e pelas

\footnotetext{
${ }^{3}$ A revista Sociologias publicou um dossiê coordenado pelo sociólogo Prof. José Vicente Tavares dos Santos e pela socióloga Prof. ․ Maíra Baumgartem, ambos da UFRGS, por ocasião do XXV Congresso da ALAS, em Porto Alegre, com a participação de articulistas latino-americanos, sobre a "produção sociológica desde 'os pensadores sociais' até a atualidade - momento da 'consolidação institucional e da mundialização da sociologia da América Latina" (Santos; Baumgarten, 2005a, p. 10).

${ }^{4}$ Mucchielli adverte que "[...] não se pode mais escrever a história longínqua de uma disciplina, qualquer que seja ela [...] pode-se escrever somente a história do processo de disciplinarização. Eis por que é indispensável trabalhar com as fronteiras disciplinares, sobre as trocas conceituais, metodológicas, metafóricas, e sobre as bases sociais destas circulações de homens e de ideias: as redes de atores, as revistas, as sociedades científicas, os congressos nacionais e internacionais" (Mucchielli, 2001, p. 38-39). Ver também o original francês: Mucchielli (1998).
} 
transformações sociais decorrentes dos ritmos diferenciados na implantação das novas economias industriais. Seus efeitos políticos, econômicos e sociais produziram uma reflexão crítica, em ruptura com as ideias dominantes do século XVIII, marcadas pelo racionalismo universalista. Em outros termos, a crise da metafísica preparou o terreno para as ciências positivas do homem e, em seus desdobramentos, da própria sociologia. Essa nova visão dos fenômenos sociais estava relacionada a alguns fatos marcantes: construíram-se Estados nacionais e centralizadores, e havia uma aspiração por unidade nacional (Alemanha, Império Austro-húngaro e Itália); emergiram fortes conflitos sociais diante das novas formas de organização da classe operária e sua ameaça ao poder da burguesia; o socialismo começava a ser difundido como uma nova forma de filosofia social e manifestava-se a necessidade de uma nova reflexão social sobre o mundo científico a partir das ciências sociais nascentes (Durand; Weil, 2006).

Nas primeiras décadas do século XIX, autores oriundos de diferentes perspectivas teóricas estabeleceram as bases epistemológicas de novas abordagens, contribuindo para a construção do campo disciplinar da sociologia. Algumas obras precursoras de Saint-Simon, Fourier, Ricardo, Tocqueville e Marx ${ }^{5}$ já sinalizavam nessa direção, embora com orientações analíticas muito diversas.

Na França, em meados do século XIX, Auguste Comte (1890) introduziu, em seu Traité de sociologie ou Système de politique positive (18511854), a "física social", integrando-a em sua "classificação ou hierarquia das ciências", no período em que instituiu a Igreja Positivista ${ }^{6}$. Nessa nova

\footnotetext{
${ }^{5}$ Refiro-me às obras de Saint-Simon, L'Industrie e Catéchisme des industriels (1823); Fourier, Le nouveau monde industriel et sociétaire (1829); Ricardo, Des principes d'économie politique et de l'impôt (1817); Tocqueville, De la démocratie en Amérique - v. I e II (1830) e v. III e IV (1840); Marx, Critique de la philosophie du droit de Hegel (1843) (com F. Engels); L'Idéologie allemande (1945-1946); e Le lutte de classes en France (1858).

${ }^{6}$ Comte (1946, p. 88-100); e Petit (2007, p. 33-62), com subtítulo A escola positiva: da sociologia à sociopolítica.
} 
abordagem, o "verdadeiro espírito científico" deve, pois, desembocar numa profunda reforma política capaz de reconciliar a ordem e o progresso, e o papel da sociologia torna-se, então, o de criar as condições de uma nova unidade orgânica à medida em que o sistema de política positiva tentava construir uma síntese conciliando os dados da natureza humana, a ordem social ou estática e a história da sociedade ou dinâmica. Embora nem sempre houvesse consciência entre seus contemporâneos, dois pensadores dominaram as ciências sociais no século XIX - além de Comte, o inglês Herbert Spencer. Este, partindo de premissas diferentes daquele, estabeleceu os fundamentos de uma "sociologia científica", dotando-a de um modelo de explicação: o organicismo. Comte, por ter associado a introdução da "sociologia" à sua fase mística da fundação da Igreja Positivista, eclipsou a importância epistemológica de seus escritos, permitindo à versão positivista de Spencer (1910) desenvolvimentos mais reconhecidos. Isso explica por que, a partir de 1870, ele conseguiu explorar melhor o núcleo científico do positivismo comteano e sua importante obra tornou-se mais reconhecida do que a do francês (Cuin; Gresle, 1996).

O espaço da sociologia, em suas origens na Europa Ocidental, desdobrou-se em três vias - a francesa, a inglesa e a alemã. Para diferenciar-se da metafísica, a ciência nascente resultou num saber quase enciclopédico, cujos traços principais, nos referidos países, foram marcados por fundamentos ainda externos à disciplina: de um lado, pelo recurso sistemático à história para compreender o direito, a economia política, a questão social e a religião; e, de outro, pelo interesse crescente pela ciência econômica, com base científica, compreendida como capaz de trazer solução à crise social que a Europa atravessava.

Apesar da emergência da sociologia e do pensamento social na França, Inglaterra e Alemanha, a institucionalização universitária da nova 
disciplina encontrou muitos obstáculos e teve de buscar caminhos alternativos. As resistências de professores de outras disciplinas já legitimadas academicamente bloquearam o acesso da sociologia ao ambiente universitário, com o temor de perderem sua hegemonia. Wolf Lepenies discute a importância do conflito entre disciplinas literárias e sociais:

Desde a metade do século XIX, a literatura e a sociologia estão em competição, cada uma pretendendo poder guiar a sociedade moderna [...] Essa controvérsia tem um papel decisivo na vida pública - primeiro na França, depois na Inglaterra e enfim na Alemanha [...]. (Lepenies, 1990, p. 1, tradução do autor)

Ele atribui este conflito à pretensa cientificidade da sociologia frente à intuição e ao imaginário na criação literária, e também às disputas com outras disciplinas consolidadas: a economia, na Inglaterra, e a história, na Alemanha.

Tais conflitos persistiram, de formas diferentes, nos três países, ao longo do século XIX, obrigando seus adeptos principais a fundar associações ou institutos privados, com recursos próprios e/ou com subsídios externos para apoiar suas iniciativas. A partir da década de 1850, constatouse que, no processo de institucionalização da sociologia, tanto na Europa como nos Estados Unidos, manifestou-se um "messianismo militante" diante "da hostilidade dos poderes estabelecidos e as desconfianças da classe dos intelectuais burgueses" (Durand; Weil, 2006, p. 37). Seus principais líderes, além de buscarem seu autofinaciamento ${ }^{7}$, vinculavam suas propostas sociais a ações voluntárias, de caráter reformista ou até mesmo socialista, por meio de associações e institutos externos às universidades. Como ressalta Mucchielli:

\footnotetext{
${ }^{7}$ Saint-Simon, além de sua fortuna pessoal, contou com o apoio de amigos para desenvolver o projeto coletivo L'Industrie (1818-1819); A. Comte também sustentou suas atividades por meio de cursos populares, publicações de livros e de subsídios da Igreja Positivista.
} 
[...] incontestavelmente, nos anos 1880-1900, assistiu-se na França ao aparecimento massivo de autores e de grupos de autores que reivindicavam o rótulo de sociólogos, que procuravam autonomizar esta ordem de saber das abordagens preexistentes e que tentavam desenvolver este ensino no seio da universidade. Foi o momento decisivo. (Mucchielli, 2001, p. 40) ${ }^{8}$.

Na França, três "escolas" foram precursoras da sociologia, embora com concepções diferentes da disciplina: a primeira, de Le Play, resultou do reconhecimento oficial dos seus trabalhos de "enquete" social e de

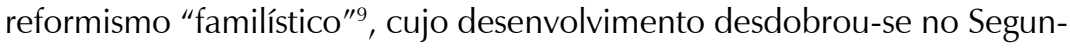
do Império (1851-1870) e, com a queda deste, reconverteu-se para responder às demandas da Terceira República (1875). A segunda, de René Worms, professor da Faculdade de Direito e do Collège de France, retomou as teses organicistas de A. Comte e H. Spencer, inscritas em sua principal obra: Organisme et société (Worms, 1896). Foi, na época, o principal construtor institucional da sociologia na medida em que fundou a Revue Internationale de Sociologie (1893), o Institut National de Sociologie (1894), a Bibliothèque Sociologique Internationale (1894) e a Societé de Sociologie de Paris $^{10}$ (1895), presidida por Gabriel Tarde ${ }^{11}$. Worms "[...]

\footnotetext{
${ }^{8} \mathrm{O}$ livro de Pierre Singaravélou (2011) introduziu, na história das ciências sociais francesas, uma vertente até então pouco estudada: as "ciências coloniais" na Terceira República, que, a partir de 1880, na conjugação entre cientificismo e a expansão colonial ultramarina, gerou a institucionalização de saberes sobre as colônias e as populações colonizadas, os quais tomaram a forma de novas disciplinas de ciências sociais (história e geografia coloniais, legislação e economia coloniais e psicologia indígena), ensinadas nas universidades e nas grandes escolas francesas.

${ }^{9}$ Le Play, engenheiro de minas, após uma viagem de observação das formas de organização de famílias operárias, escreveu o livro Les ouvriers européens (1855) e fundou a Société d'Économie Sociale (1856). Dedicou-se a fazer pesquisas para empresários e autoridades do governo de Napoleão III e criou a primeira revista de ciências sociais: Reforma Social (1881). Na Terceira República, seus discípulos fizeram pesquisas sobre a evolução sindical e contribuíram para a criação do Ministério do Trabalho (Durand; Weil, 2006, p. 38-9).

${ }^{10}$ Essa sociedade tinha uma perspectiva eclética e nela colaboravam antropólogos, historiadores, filósofos e pesquisadores estrangeiros.

${ }^{11}$ Tal fato explica o sucesso de G. Tarde e de seu livro Les lois de l'imitation (1890) na França e no exterior (Mucchielli, 2001).
} 
seguiu uma estratégia puramente institucional, pois foi o primeiro a tentar a fundação da sociologia em instituições" (Mucchielli, 2001, p. 45), e com isso deu visibilidade institucional e transnacional à sociologia. A terceira escola, liderada por Émile Durkheim (1858-1917) ${ }^{12}$, filósofo com formação na École Normale Supérieure de Paris e agrégé ${ }^{13}$ em filosofia, foi quem efetivamente fundou a "escola francesa de sociologia" no período republicano, em que a universidade francesa estava sendo reformada $(1880)^{14}$, visando enfrentar a hegemonia intelectual e científica da Alemanha. Nas faculdades de Ciências e Letras, foram reorganizadas as carreiras universitárias e o recrutamento dos professores com um novo sistema de seleção meritocrático (agrégation). No plano das disciplinas, algumas foram mais valorizadas - história, geografia e ciências da educação - com resistências em relação à sociologia e à psicologia. Em grande medida, essas resistências decorreram dos conflitos crescentes entre as ciências sociais nascentes e disciplinas cujo status estava historicamente consolidado, tais como a filosofia, a história e a literatura (Lepenies, 1990).

Durkheim "foi o último a chegar nessa história". Diferentemente dos outros antecessores, "[a] sociologia era para ele uma vocação pessoal e uma missão política no sentido mais nobre [...]". Tinha um sentido de missão e uma concepção otimista da ciência, pois em sua concepção, ela "[...] iria permitir a compreensão da crise social e moral da sociedade francesa e

\footnotetext{
${ }^{12}$ Sobre Émile Durkheim, ver o dossiê 100 anos sem Durkheim, 100 anos com Durkheim, coordenado pelos professores: Raquel Weiss, Rafael Faraco Benthien e Clarissa Eckert Baeta Neves (Sociologias, v. 19, n. 44, 2017).

${ }^{13}$ Trata-se de concurso, após o doutoramento, para o recrutamento de professores de liceus e universitários. É uma das condições para aceder ao posto de professor em direito, ciências econômicas, ciência política e gestão. Na França, a agrégation tem origem remota, os primeiros docteurs-agrégés foram instituídos por J. B. Colbert (ministro de Luís XIV). Seu estatuto atual foi estabelecido pelo Decreto №72.580, de 4 de julho de 1972.

${ }^{14}$ Era do interesse do governo francês que jovens professores fossem conhecer as universidades alemãs e pudessem contribuir para a reforma da universidade conduzida por Louis Liard (ver Charle; Verger, 2012).
} 
indicar os remédios para restabelecer a solidariedade entre os membros da sociedade, a ciência do Homem por excelência" (Mucchielli, 2001, p. 46). Nesse novo contexto político, o jovem filósofo Émile Durkheim foi nomeado chargé de cours en pédagogie et science sociale, em 1897, na Faculdade de Letras da Universidade de Bordeaux ${ }^{15}$, após ter retornado de uma bolsa de estudos na Alemanha (Leipzig Berlim, 1885-1886) ${ }^{16}$.

Em sua nova cátedra, Durkheim ministrou separadamente uma série de conferências sobre pedagogia e um "curso público de ciência social"17, o qual teve astuciosa apresentação. Fournier reproduz as hábeis palavras introdutórias de Durkheim em seu primeiro curso na Universidade Bordeaux:

Um sábado de dezembro de 1887, em um anfiteatro da Faculdade de Letras, o novo professor, todo febril, toma a palavra: "Senhores, incumbido de ensinar uma ciência que nasceu ontem e que não dispõe ainda que de um pequeno número de princípios estabelecidos, seria temerário de minha parte não estar aterrorizado pelas dificuldades da tarefa. Eu creio, no entanto, que nas nossas universidades, ao lado das cátedras que ensinam a ciência feita de verdades reconhecidas, há lugar para outros cursos, onde o professor constrói a ciência à medida que ele ensina; onde ele encontra nos ouvintes colaboradores enquanto estudantes, onde ele busca com eles, tateia com eles, às vezes erra com eles" (Fournier, 2007, p. 125-6).

Em 1896, fundou a primeira revista de sociologia - L'Année Sociologique -, periódico semestral publicado até 1926 que teve o

\footnotetext{
${ }^{15}$ Durkheim teve de esperar até 1906 para chegar à Sorbonne e tornar-se suplente da cadeira de Ciência da Educação e até 1913 para assumir efetivamente o ensino da sociologia (Cuin; Gresle, 1996).

${ }^{16}$ Sobre as missões dos professores franceses à Alemanha e as análises dos relatórios avaliativos sobre a experiência, ver o capítulo Vue de l’Allemagne, em Charle (1994, p. 21-60).

${ }^{17}$ Os principais temas dos cursos de Durkheim, em sociologia, foram: "A solidariedade social", "A família", "O suicídio"; e as conferências em pedagogia: "Educação moral", e "Educação da Inteligência", "História da Pedagogia", "Pedagogia francesa do séc. XVIII e XIX" (Fournier, 2007).
} 
mérito de aglutinar um grupo de discípulos ${ }^{18}$, e sua liderança na área foi preponderante quando chegou à Sorbonne, em 1905. A revista reapareceu posteriormente com o nome de Annales Sociologiques (1934$1942)^{19}$, na qual escrevia um grupo selecionado de sociólogos franceses ${ }^{20}$. As publicações fundadoras da sociologia francesa, La division du travail social (1893), Les règles de la méthode sociologique (1895), Le suicide (1897) e Les formes élémentaires de la vie religieuse (1912) tiveram um impacto imediato e lhe deram reputação. Para Mucchielli:

É preciso ainda insistir no papel infeliz do acaso no processo de institucionalização da sociologia na França. O acaso está aqui representado pelo início da Primeira Guerra Mundial, desastrosa para o conjunto da juventude intelectual francesa, mas que parece ter atingido mais particularmente os sociólogos franceses e seus aliados mais próximos. No conjunto dos alunos de Durkheim, Mauss e Hubert, uma dezena de jovens pesquisadores promissores são mortos nos campos de batalha. Entre eles, o próprio filho de Durkheim desaparece [...] Afinal de contas, é uma hecatombe que a sociologia durkheimiana terá dificuldade em superar! (Mucchielli, 2001, p. 51).

\footnotetext{
${ }^{18}$ O próprio Durkheim, Paul Fauconnet, Célestin Bouglé, Marcel Mauss, Maurice Halbwachs, François Simiand, entre outros. Cabe registrar que em 1903 foi feito um primeiro balanço do ensino das ciências sociais (ver Hauser, 1903).

${ }^{19} \mathrm{Na}$ década de 1920, fracassou o relançamento da revista L'Année Sociologique (interrompida entre 1913 e 1925) e a escola de Durkheim teve um declínio em sua influência pela ausência de um novo líder e devido ao fato de os principais membros do grupo se dispersarem em diferentes instituições (Fournier, 2007, pp. 329-63).

${ }^{20} \mathrm{O}$ fator político era igualmente muito favorável no seio da juventude intelectual: de um lado, a maioria da equipe de Durkheim era composta de jovens socialistas (Durkheim mesmo ficou afastado da política, mas são conhecidas suas simpatias e sabe-se que era amigo pessoal de Jaurès); de outro lado, a totalidade de sua equipe estava engajada na defesa do capitão Dreyfus, acusado de traição. Para Charle, o Affaire Dreyfus estabelece o surgimento dos intelectuais como um ator coletivo (Charle, 1990; Mucchielli, 2001).
} 
$\mathrm{Na}$ Inglaterra, depois da hegemonia do evolucionismo spenceriano, Barnes analisou os avanços da sociologia com outras perspectivas analíticas: a filosofia supranacional de B. Kidd; a filosofia evolucionista a serviço da "democracia e reforma social", de L. T. Hobhause; a aplicação dos métodos etnográficos para a moral e o casamento, de E. A. Westermarck; a reabilitação da teoria do matriarcalismo, de R. Briffault; a sociologia aplicada; a pesquisa social, o regionalismo e o planejamento urbano, de P. Geddes e V. Braudfort; e a "base sócio-psicológica da reconstrução social", de G. Wallas.

Após a morte de Spencer (1903) foi organizada na Inglaterra uma sociedade privada de sociologia que, em 1904, denominou-se Instituto de Sociologia, da mesma forma como o fizera alguns anos antes Worms, na França. Os primeiros cursos universitários datam de 1907, com Leonard Hobhouse ${ }^{21}$, na Universidade de Londres (1907), reconhecido como o primeiro professor de sociologia do Reino Unido, e Edward Westermarck, professor da mesma universidade, considerado o primeiro sociólogo de orientação darwiniana e autor de um livro clássico, The History of Human Mariage, publicado em 1891. Nessa fase fundacional da sociologia inglesa, há predominância de uma discussão muito eclética e pluridisciplinar, testemunhando o interesse da categoria intelectual por questões sociais, especialmente a partir da edição inglesa de 1891 do livro de F. Engels sobre as condições de vida dos operários na indústria na Inglaterra vitoriana e a contribuição de K. Marx ${ }^{22}$.

Harry Barnes, em sua obra An introduction to the history of sociology, na qual reúne ensaios de diversos autores, dedica um longo capítulo

\footnotetext{
${ }^{21}$ Hobhouse escreveu outros livros: The Labour Movements (1893), Social Evolution and Political Theory (1911), Liberalism (1911) e foi o primeiro editor da The Sociological Review, a mais antiga revista inglesa na área.

${ }^{22} \mathrm{~A}$ amplitude dos campos abordados por K. Marx e F. Engels que trabalham com conceitos (classe, alienação, ideologia e divisão do trabalho) que foram sempre referidos por sociólogos inspirados no marxismo. Este comentário é válido também para O Capital e A Ideologia Alemã, que são obras de maturidade e analisam as determinações entre as relações econômicas e a superestrutura jurídica e política, com ênfase na teoria das classes sociais em escritos mais sociológicos (O 18 Brumário de Luís Bonaparte ou As Lutas de Classe na França). Marx analisa mais em detalhe as classes e as frações de classe: burguesias industrial, financeira e comercial, pequena burguesia, classe camponesa, proletariado e lumpemproletariado (Durand; Weil, 2006).
} 
sobre os sociólogos em países germânicos, traçando um panorama que engloba o pensamento de W. Wundt, o sistema sociológico de F. Tönnies ("comunidade e sociedade"), as formas de interação social de G. Simmel, a análise sociológica de Max Weber (por Talcott Parsons), a filosofia social e econômica de W. Sombart (a sociologia do capitalismo), entre outros.

Em 1872, na Alemanha, foi fundada por G. Schmoller a Associação para a Política Social, de "tendência reformista", e para a qual Max Weber $^{23}$ realizou o primeiro estudo sobre os camponeses da Prússia: $A$ situação dos trabalhadores rurais na Alemanha a leste do Rio Elba (189091). "Essa primeira obra sua no campo da economia política, de 900 páginas, foi escrita com a rapidez de um raio, enquanto Weber dava seus primeiros cursos de direito" (Weber, 2003, pp. 156-165). Este fundou, em 1903, com E. Jaffe e W. Sombart, a revista Arquivos de Ciências Sociais e de Política Social, na qual escreve, no ano seguinte, um "manifesto" em favor da "objetividade do conhecimento" e sua obra clássica: "A Ética Protestante e o Espírito do Capitalismo. Sua posição sobre a "[...] neutralidade do sábio diante da intervenção estatal vai colocá-lo em minoria na Associação que defendia a intervenção dos cientistas na vida política e econômica" (Durand; Weil, 2006, p. 42) ${ }^{24}$. Nesse período, "o estatuto da sociologia permanece muito tempo problemático": Weber somente ocupará tardiamente uma cátedra de Sociologia (1919). Quanto a Ferdinand Tönnies, este não consegue uma cátedra de filosofia, associa-se ao

\footnotetext{
${ }^{23} \mathrm{M}$. Weber (1864-1920) estudou direito em Berlim, Heidelberg e Gottingen. Doutorou-se em Berlim (1889) com uma tese sobre a história econômica medieval; em 1894, entrou na Universidade de Friburgo e, em 1896, conquistou a cátedra de economia política na Universidade de Heidelberg, onde permaneceu assiduamente.

${ }^{24}$ O livro de Ringer (2000), O declínio dos mandarins: A Comunidade Acadêmica Alemã (1890-1930), é uma leitura obrigatória, porque oferece uma perspectiva original sobre a história do que ele denominou de "intelectuais mandarins", professores universitários (os cientistas sociais e humanistas, especialmente) que exerceram um papel central na formação da opinião de alemães cultos. Esse declínio ocorre, paradoxalmente, entre 1890-1930, período posterior à queda do Império de Guilherme II e o advento da República de Weimar.
} 
Institut International de Sociologie de Worms e somente em 1913 chega a ensinar sociologia. Simme ${ }^{25}$ não conseguiu a cátedra a que aspirava na Universidade de Berlim e teve de assumir, em 1914, uma de filosofia e sociologia na Universidade de Estrasburgo.

Na Alemanha, a principal "concorrência disciplinar" foi entre a sociologia e a história:

A sociologia em moda na Europa ocidental enfrenta na Alemanha uma recusa política, porque não somente admitia a ruptura escandalosa entre a sociedade e o Estado, mas chegava até a aprová-la como condição necessária de seu direito à existência científica. Ela provocava, além disso, uma reação proveniente da teoria das ciências porque questionava o caráter específico dos fenômenos históricos e se arrogava ao papel de concorrente da historiografia. (Lepenies, 1990, p. 234)

Em 1919, por iniciativa de Max Weber, organizou-se o primeiro departamento de sociologia na Universidade Louis-et-Maximilien de Munique.

A constituição histórica das ciências sociais na Europa, portanto, relaciona-se diretamente à progressiva implantação das condições de exercício profissional e legitimação da prática científica como um elemento de diferenciação interna ao campo cultural (Charle, 1990). Nesse processo, são determinantes as transformações econômicas, políticas educacionais e científicas, a concorrência internacional e as novas condições políticas que pautam os modelos de definição da atividade intelectual (Charle, 2001). Isso ocorre, principalmente, pelo confronto entre o espaço de inserção e diversificação disciplinar e o tradicional, controlado por forças políticas, econômicas e intelectuais, buscando continuamente reduzir a progressiva autonomização do campo cultural e universitário

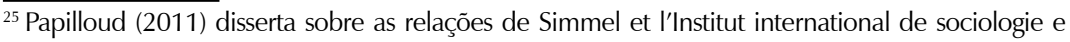
sobre Durkheim et l'Année Sociologique. O autor menciona o papel de Célestin Bouglé da ENSup na intermediação das discussões entre o sociólogo francês e o alemão (ver Bouglé,1896).
} 
aos imperativos externos e ao poder temporal (Bourdieu, 1984; Charle, 1994; Karady, 1976).

\subsection{A institucionalização da sociologia nas universidades americanas}

No período aqui analisado, o desenvolvimento da sociologia americana pode ser dividido em três fases: 1) nas duas últimas décadas do século XIX começam os cursos de sociologia em diversas universidades; 2) de 1900 e 1920, a sociologia se difundiu nas faculdades de humanidades e nas letras e, em 1905, foi criada a American Sociological Society; 3) 1920 a 1935 é a fase da "consolidação", quando foram instituídos os mais importantes centros de ensino e pesquisa, ampliaram-se os cursos de graduação e de pós-graduação, multiplicaram-se as revistas especializadas, a formação de equipes de pesquisa, os contatos internacionais e o desenvolvimento de subdisciplinas especializadas (Eufrasio, 1995). Nesse período, veio a predominar a orientação que se desenvolveu em Chicago, caracterizada por uma ecologia humana e uma psicossociologia avant la lettre, e, secundariamente, a orientação surgida em Colúmbia; na década de 1930, pelo prestígio e a importância que ganhou dentro e fora dos círculos acadêmicos, a sociologia veio a ser conhecida como "a ciência americana", difundindo-se e influenciando a sociologia de outros países.

Nos Estados Unidos, a sociologia foi ensinada pela primeira vez na Universidade de Kansas ${ }^{26}$. Frank Blackmar (1854-1931), após ter feito seu $\mathrm{PhD}$ na Universidade John Hopkins, foi professor no departamento de

\footnotetext{
${ }^{26}$ Uma das primeiras e mais abrangentes análises sobre a história da sociologia numa perspectiva internacional é um reader de $\mathrm{H}$. Barnes, da Universidade de Colúmbia, publicado em 1917. Nesta obra centenária, o autor apresenta um painel completo do estado da arte na sociologia, desde a Antiguidade, passando pelo papel da Igreja até a formação do Estado Nacional, designada como "filosofia social". A partir do final do século XVIII e primeiro terço do século XIX, analisa a emergência da sociologia como uma "ciência normativa" com Saint Simon, Comte e Spencer na Europa e os pioneiros da sociologia nos Estados Unidos: L. H. Morgan, Sumner, Wardt e Gumplowicz.
} 
história e sociologia (1899) e depois no departamento de sociologia e economia (1899-1912), tendo sido chefe do departamento de sociologia, de 1899 a 1912. Ele escreveu, em 1907, um dos primeiros livros da nova disciplina: Elements of Sociology ${ }^{27}$. O termo sociologia já era utilizado por professores de outras universidades americanas, tais como Grahan Summer, em Yale, desde 1876, e na Universidade de Colúmbia, em Nova York, a partir de 1890. Mas foi em 1892, na Universidade de Chicago, fundada com apoio de evangélicos e da filantropia capitalista, que houve a mais importante presença institucional da sociologia. Albion W. Small (1854-1926) ${ }^{28}$, colega de Blackmar na Universidade John Hopkins, dirigiu o primeiro departamento da disciplina por três décadas e escreveu o primeiro manual sobre o assunto (1894). Para ele, a sociologia era uma ciência positiva, embora procurasse se afastar da influência de A. Comte e praticasse uma espécie de "sociologia histórica", por influência de Marx nos seus estudos na Alemanha. Small fundou a revista American Journal of Sociology (1896) que, em suas primeiras edições, foi "muito aberta à sociologia europeia", publicando artigos de Georg Simmel e da Escola de Le Play.

A Universidade de Chicago $^{29}$ foi criada numa cidade de grande complexidade urbana e com acentuadas desigualdades econômicas e sociais, o que criou desafios para os praticantes da nova disciplina. Tais condições produziram, de um lado, um recrutamento de professores de origem pluridisciplinar e, de outro, uma prática acadêmica combinando

\footnotetext{
${ }^{27}$ Os primeiros livros foram sobre temas históricos: Spanish colonisation in the Southwest (1890) e The history of human progress (1896).

${ }^{28}$ Small, após concluir os estudos teológicos (1876-1879), estudou na Alemanha, nas universidades de Leipzig e Berlim, história, economia social e política (1879-1881). Nos Estados Unidos, formou-se em história constitucional na Universidade John Hopkins e sua tese doutoral intitulou-se The Beginnings of American Nationality.

${ }^{29}$ Chicago, uma das maiores cidades americanas, preocupava as elites econômicas com os governos locais ineficientes e corruptos. Ademais, com uma configuração urbana com forte presença de imigrantes de origem europeia (ingleses, alemães e norte-europeus), havia grande circulação de ideias socialistas e anarquistas (ver Hays, 1957).
} 
engajamento social com organizações de solidariedade junto aos setores populares, denominada, à época, de "reforma" ${ }^{30}$. Seus principais atores foram recrutados na elite econômica da cidade, nas classes médias e entre profissionais liberais (juristas e médicos), pastores protestantes, professores universitários e jovens mulheres graduadas em ciências sociais, que se tornaram administradores, professores de universidade, pesquisadores e, sobretudo, trabalhadores sociais. Os professores de ciências sociais "[...] especialmente, sociólogos, economistas, politólogos e filósofos - ocuparam um lugar importante nesse movimento cuja história está, assim, estreitamente vinculada ao desenvolvimento inicial dessas disciplinas nos Estados Unidos" (Chapoulie, 2001, p. 28). Para penetrar melhor no ambiente reformista dentro do qual se organizou a nova Universidade de Chicago ${ }^{31}$, é preciso mencionar que, três anos antes da sua abertura, eclodiu um momento simbólico de articulação entre a sociologia em processo de constituição e os movimentos de ação social nos bairros periféricos da cidade ${ }^{32}$.

No que concerne ao conteúdo do ensino da sociologia, caberiam duas considerações. Primeiro, as teorias dos líderes da nova disciplina são diversas, mas se inscrevem nas concepções de A. Comte e H. Spencer; os programas dos cursos dos sociólogos da primeira geração consideram a sociologia como "a ciência social geral, disciplina sintética", que coordena "as descobertas" das disciplinas específicas (economia política, história,

\footnotetext{
${ }^{30} \mathrm{O}$ movimento de reforma (progressive era) mantinha uma relação próxima com as ciências sociais e sua liderança contribuiu para a fundação, nos bairros populares, de estabelecimentos (settlements) que ofereciam moradias e serviços aos habitantes do bairro. Essas ações sociais inspiraram-se em jovens intelectuais britânicos que se instalaram, em 1884, num bairro popular, Toynbee Hall, a leste de Londres, para promover educação e arte.

${ }^{31}$ A nova universidade de Chicago era privada, ocupando o espaço do Colégio Batista e teve um importante apoio financeiro dos Rockefeller (35 milhões de dólares em 20 anos).

${ }^{32}$ A filha do senador Quaker, Jane Addams, instalou-se, juntamente com uma de suas antigas alunas, numa casa de um bairro popular e de imigrantes - Hall House - com o objetivo de oferecer serviços sociais, local de reuniões de cunho religioso e era menos elitista que em Londres (Chapoulie, 2001).
} 
ciências políticas ou antropologia). Em segundo lugar, as elites protestantes pretendiam que a sociologia pudesse fornecer uma "[...] base científica ao evangelho social (social gospel) que constitui a forma laicizada do proselitismo da geração precedente" (Chapoulie, 2001, pp. 37-8). Nessa ótica, a evolução do pensamento social nos Estados Unidos já revela uma reação progressiva contra a influência de H. Spencer (Fleming, 1963).

Se a cooperação internacional em sociologia começou pioneiramente na França - com R. Worms, ainda no século XIX -, nos Estados Unidos, somente em 1905 foi instituída a American Sociological Association por Lester Frank Ward, seu primeiro presidente.

\section{Reprodução e institucionalização internacional da sociologia na América Latina}

O processo de construção da sociologia na América Latina desenvolveuse em função de condicionantes históricos, próprios a cada sociedade, e das dinâmicas universitárias dos países. Esse processo permite observar que há padrões diferenciados de "disciplinarização", em termos nacionais, a partir de modelos de referência dos países fundadores. A elaboração de um quadro geral sobre a construção institucional das ciências sociais, com ênfase na sociologia, na América Latina, de suas origens na década de 1930 até a de 1970, permite observar um padrão diferenciado entre os cinco países pesquisados: Argentina, Brasil, Chile, México e Uruguaii3 ${ }^{33}$

\footnotetext{
${ }^{33}$ Essa análise apoia-se, em grandes linhas, no capítulo "Ciências Sociais na América Latina em perspectiva comparada: Argentina, Brasil, Chile, México e Uruguai", publicado em Trindade, 2007.
} 
Sociologias, Porto Alegre, ano 20, no 47, jan/abr 2018, p. 210-256

Quadro 1 - Construção da Sociologia na América Latina, 1887-1967

\begin{tabular}{|c|c|c|}
\hline Ano & Instituições & País \\
\hline 1877 & Instituto de Ciencias Sociales ${ }^{34}$ & Venezuela \\
\hline 1882 & Curso de Sociología - Universidad de Bogotáa & Colômbia \\
\hline 1898 & Cátedra de Sociología - Facultad de Filosofía y Letras (UBA) & Argentina \\
\hline 1907 & Cátedra de Sociología - Universidad Nacional de Córdoba (UNC) & Argentina \\
\hline 1908 & Cátedra de Sociología - Facultad de Derecho (UBA) & Argentina \\
\hline 1909 & Cátedra de Sociología - Universidad Nacional de La Plata (UNLP) & Argentina \\
\hline 1914 & Cátedra de Sociología - Universidad de Litoral (UNL) & Argentina \\
\hline 1915 & Cátedra de Sociología - Facultad de Derecho (UDELAR) & Uruguai \\
\hline 1930 & Instituto de Investigaciones Sociales (UNAM) & México \\
\hline 1931 & Colegio Libre de Estudios Superiores (CLES) & Argentina \\
\hline 1933 & Escola Livre de Sociologia e Política (SP) & Brasil \\
\hline 1934 & Faculdade de Filosofia, Ciências e Letras (USP) & Brasil \\
\hline \multirow[t]{3}{*}{1939} & Faculdade Nacional de Filosofia (Universidade do Brasil) & Brasil \\
\hline & Revista Mexicana de Sociología & México \\
\hline & Revista Interamericana de Sociología - Caracas & Venezuela \\
\hline 1940 & Fondo de Cultura Económica (Sección de Obras de Sociología) & México \\
\hline 1943 & Centro de Estudios Sociales (Colegio de México) & México \\
\hline 1946 & Instituto de Investigaciones Sociológicas (Universidad de Chile) & Chile \\
\hline 1947 & Instituto de Sociología (UBA) & Argentina \\
\hline 1948 & Comisión Económica para América Latina (CEPAL) & Chile \\
\hline 1950 & Asociación Latinoamericana de Sociología (ALAS) ${ }^{36}$ & Suíça \\
\hline 1951 & Escuela Nacional de Ciencias Políticas y Sociales (UNAM) & México \\
\hline 1953 & Instituto Brasileiro de Economia, Sociologia e Política (IBESP) & Brasil \\
\hline
\end{tabular}

continua

\footnotetext{
${ }^{34}$ Ver Blanco, 2005, p.23.

35 “La Universidad de Bogotá abrió el primero curso de sociología en el mundo que se anticipó así en diez años al inaugurado en Chicago en 1892" (Idem, Ibidem).

${ }^{36}$ Fundada em 1950 por um grupo de sociólogos latino-americanos, reunidos por ocasião do primeiro congresso mundial de sociologia. Organizada pela Association Internationale de Sociologie e, mais tarde, International Sociological Association (ISA) (Blanco, 2005).
} 
continuação

\begin{tabular}{|c|l|c|}
\hline Ano & \multicolumn{1}{|c|}{ Instituições } & País \\
\hline \multirow{3}{*}{1955} & Instituto Superior de Estudos Brasileiros (ISEB) & Brasil \\
\cline { 2 - 3 } & Centro Brasileiro de Estudos Pedagógicos (CBPE-RJ) & Brasil \\
\cline { 2 - 3 } & Departamento de Sociologia (UBA) & Argentina \\
\cline { 2 - 3 } & Centro Latino-americano de Pesquisas Sociais (CLAPCS) & Brasil \\
\hline \multirow{3}{*}{1958} & Instituto de Ciências Sociais (Universidade do Brasil) & Brasil \\
\cline { 2 - 3 } & Escuela de Sociología (FLACSO) & Chile \\
\cline { 2 - 3 } & Instituto de Desarrollo Económico y Social (IDES) & Argentina \\
\cline { 2 - 3 } & Curso de Sociologia e Política (PUC-RJ) & Brasil \\
\hline 1959 & Escuela de Sociología (Pontificia Universidad Católica) \\
\cline { 2 - 3 } & Carrera de Sociología (Universidad Católica) & Argentina \\
\hline 1962 & Instituto y Carrera de Sociología (Universidad El Salvador) & Argentina \\
\hline 1963 & Centro de Sociología Comparada (Instituto Di Tella) & Argentina \\
\cline { 2 - 3 } & Centro de Investigaciones Sociales (Instituto Di Tella) & Argentina \\
\hline 1964 & Centro de Investigaciones Sociales (CIS) & Argentina \\
\hline 1967 & Consejo Latinoamericano de Ciencias Sociales (CLACSO) & Argentina \\
\hline
\end{tabular}

Fonte: Este quadro reproduz e amplia o publicado em Trindade (2004, pp. 156-157).

\subsection{A importação da sociologia na Argentina, Brasil, Chile, México e Uruguai}

$\mathrm{Na}$ análise comparativa das ciências sociais na América Latina, observa-se, de forma análoga às instituições fundadoras europeias e norte-americanas, que elas estiveram submetidas aos condicionantes do contexto sociopolítico de cada país e com uma orientação reformista e crítica. Germani (1964), em sua análise sobre a recepção da sociologia na América Latina, ressalta que:

[...] no plano do ensino e da orientação teórica a sociologia de nossos países refletiu o estado da disciplina nos centros intelectuais do ocidente. Este fato demonstrava - e demonstra atualmente o problema da recepção de teorias e métodos de outra parte. [...] Há aqui dois fatores principais. 
Em primeiro lugar, teorias e métodos sociológicos ainda que se formulem em termos de universalidade são produtos históricos [...] [E] é possível não possam transladar-se mecanicamente a outro tipo de realidade [...] A universalidade da ciência - e de suas contribuições - não deriva da aplicação cega de modelos teóricos, venham de onde venham, senão da continua interação entre a teoria e a realidade concreta. (Germani, 1964, p. 4) $)^{37}$

O percurso das ciências sociais na região esteve associado à análise dos problemas concretos (macro ou micro, segundo os períodos e países), assim como à vontade dos "pensadores sociais", e depois sociólogos, de enfrentá-los (Liedke Filho, 2005). Isso propiciou uma maior incidência dos níveis ideológicos no discurso da academia, assim como uma tendência a vincular a prática acadêmica da sociologia à política e aos governos.

As práticas da "pré-história" da sociologia foram muito influenciadas por correntes provenientes de disciplinas-mãe europeias ou norteamericanas. O positivismo, em sua versão saint-simoniana e comteana, foi a teoria inspiradora no nascimento das ciências sociais. No entanto, correntes antipositivistas fizeram o contraponto, especialmente com a "filosofia do espírito", de Victor Cousin, e o "espírito dos povos" dos pensadores alemães. A obra de Ward introduzirá, no início do século XX, a influência americana. Apesar da incorporação dos currículos durkheimianos e de outros autores contemporâneos, a investigação empírica com aspirações teóricas ainda era limitada.

Em fins do século XIX, fundaram-se as primeiras "cátedras" de sociologia. Estas foram os pontos de partida de um processo de institucionalização na medida em que implicavam o reconhecimento da disciplina como

\footnotetext{
${ }^{37}$ Sobre a perspectiva latino-americana da sociologia e sua relação com outras disciplinas (economia, história, geografia e antropologia), ver o livro que reúne os trabalhos apresentados na Conferência sobre Estudos Latino-americanos realizada no Hotel Gloria (RJ) de 29-31 de março de 1965, publicado pelo Centro Latino-Americano de Pesquisas em Ciências Sociais, dirigido por Manuel Diegues Junior (s/d).
} 
campo de conhecimento legítimo a ser incorporado ao sistema acadêmico. As cátedras estiveram vinculadas, inicialmente, a áreas de formação profissional como o direito e a filosofia e, mais tarde, à economia ou educação. O fato de que a maioria dos países tenha enfrentado fortes tensões políticas, sociais e até revoluções influenciou a dinâmica da "disciplinarização" da sociologia desde a sua importação, no final do século XIX.

$\mathrm{Na}$ etapa fundacional, os sociólogos - mesmo exercendo atividades num âmbito acadêmico - tinham uma relação predominantemente crítica, e até contestatória, com as políticas governamentais, e muitos se vincularam a movimentos sociais ou partidários. Tal tipo de atuação, iniciada com os debates em torno da revolução mexicana (1910) e seus desdobramentos, seria posteriormente referenciado à corrente de matriz marxista ou de humanismo cristão progressista.

A esta altura, cabe a pergunta: até que ponto esses antecedentes serviram efetivamente como base do processo de emergência e institucionalização da sociologia? A resposta supõe que se levem em consideração as diferenças e as pautas específicas dos países quanto a continuidade, mudanças e rupturas históricas ${ }^{38}$. Nessa ótica, num extremo, situam-se México e Brasil, com uma significativa continuidade institucional e, no outro, a Argentina e Chile, com rupturas com as formas precedentes de institucionalização. O Uruguai encontra-se numa situação intermediária:

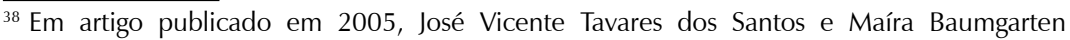
estabeleceram uma periodização sobre a sociologia na América Latina que compreende desde a herança intelectual da sociologia do século XIX até o início do século XX, passando pela sociologia de cátedra 1890-1950, pela "sociologia científica", pela configuração da Sociologia Crítica (1950-1973) até a consolidação institucional e a mundialização da sociologia da América Latina, a partir do ano 2000. Essa periodização coincide, parcialmente, com a adotada neste artigo, mas, estando ele circunscrito à reprodução e à institucionalização internacional da sociologia na América Latina, tem um foco diferente, tanto em sua abrangência quanto em sua perspectiva analítica. Nesse sentido, aos interessados em conhecer as outras etapas do desenvolvimento da sociologia na América Latina, ver: Santos; Baumgarten, 2005b.
} 
os cientistas sociais formados na fase pré-sociológica participarão da nova institucionalização, ampliando sua forma intelectual de atuação ${ }^{39}$.

Nessa fase inicial da sociologia, dois países diferem no processo de continuidade/ruptura: o México atingiu o nível máximo em função dos desdobramentos da Revolução Mexicana e da incorporação posterior das diversas variantes acadêmicas do marxismo. Na Argentina, desde o golpe de Uriburu, em 1930, durante o longo período do governo peronista, do retorno à democracia, em 1955, e com o advento das ditaduras militares, esse vínculo político-ideológico, incluído o período da criação por Gino Germani $^{40}$ da carreira de sociologia na Universidade de Buenos Aires (UBA), foi virtualmente inexistente.

No caso do México, ainda sob o impacto do debate ideológico radicalizado pela Revolução de 1910, a primeira instituição que adotou a disciplina de sociologia foi o Instituto de Investigaciones Sociales (IIS), em 1930, na Universidade Autônoma do México (UNAM). A partir do governo Cárdenas, na década de 1930, foi-se constituindo um sistema político autoritário civil, com partido dominante: o Partido Revolucionário Institucional (PRI). Era um Estado autoritário civil, numa sociedade pouco mobilizada, no qual o governo deu muito apoio às ciências sociais. Embora tenha vivenciado um endurecimento da hegemonia do PRI, sem alternância no poder, tornando-se quase um partido único, o México não experimentou ditaduras militares, e o governo manteve um clima de liberdade e autonomia das universidades frente ao poder.

\footnotetext{
${ }^{39}$ Há autores que distinguem os "pensadores sociais" dos sociólogos. Para Liedke, "O período dos Pensadores Sociais corresponde historicamente ao período que se estende das lutas pela Independência das nações latino-americanas até o início do século XX [...]". A teoria social desses tendia "[...] a ser elaborada por pensadores sob a influência de ideias filosófico-sociais europeias ou norte-americanas [...]" (Liedke Filho, 2003, p. 377). Este artigo restringe-se ao seu objeto, as origens institucionais da sociologia, não analisando o período dos "pensadores sociais" ou "ensaístas" e apenas aceitando os sociólogos de cátedra por estarem associados ao processo de institucionalização da disciplina.

${ }^{40}$ Para conhecer seus escritos ver Blanco e Germani (2006) e Germani (2004) - deste último, ver especialmente os capítulos 1 e 2 (p. 21-94). As sociologias argentina e latino-americana foram profundamente marcadas por sua obra que empreendeu uma busca da fundamentação científica e do distanciamento da filosofia social, sem dispensar, todavia, o engajamento diante das questões sociais. Debruçou-se particularmente sobre os métodos da pesquisa sociológica.
} 
O processo de institucionalização da sociologia começou no México, em grande medida, em função de três fatores favoráveis: a chegada do intelectual espanhol José Medina Echavarría ${ }^{41}$, juntamente com o grupo de exilados espanhóis da Guerra Civil; o seu papel na direção editorial da Fondo de Cultura Económica ${ }^{42}$; a criação do Instituto de Investigaciones Sociales da UNAM e do Colegio de México, no início dos anos 1940. Este último fundado por exilados espanhóis reunidos, primeiro, em torno da Casa de España (1938) (Garciadiego, 2000, p. 117-23).

O desenvolvimento das Ciências Sociais no México foi singular quando comparado com os outros países ${ }^{43}$. Mais tarde, com as ditaduras militares no Cone Sul, o México teve a forte a presença de intelectuais exilados da Argentina, Brasil e Chile, e viabilizou, em seu espaço universitário, grandes avanços na teoria e na prática das ciências sociais. Após o período de radicalização do modelo científico-crítico da década de 1930, o marxismo acadêmico foi a orientação dominante entre os anos 19601970; e, finalmente, as ciências sociais diversificaram-se, num contexto de revalorização da democracia, sem um paradigma dominante.

\footnotetext{
41 J. M. Echavarría (1903-1977) nasceu na Espanha, exilou-se no México durante a Guerra Civil; doutorou-se em direito na Universidade Central de Madri (1929) e prosseguiu seus estudos em sociologia na Alemanha, na Universidade de Masburgo (1930-1931). Permaneceu no México de 1939-1945, onde foi o primeiro catedrático de sociologia da UNAM e do Colégio do México. Dirigiu as publicações dos clássicos da sociologia alemã na Fondo de Cultura Económica (FCE), tendo traduzido do alemão Economia y Sociedad, de Max Weber. Ingressou na CEPAL no Chile (1952) e foi designado como um dos 'experts' da UNESCO, sendo nomeado primeiro diretor da FLACSO/Chile (1957-1959), onde permaneceu até seu falecimento. Principais obras: Introducción a la sociología contemporánea (1936), La Cátedra de Sociología (1939), Sociología: teoría e técnica (1941), Responsabilidad de la inteligencia (1943), Aspectos sociales del desarrollo económico (1959), Consideraciones sociológicas del desarrollo económico (1963).

${ }^{42}$ José Medina Echavarría dirigiu a "sección de sociología" da editora FCE (ver Arciniega, 1994).

${ }^{43} \mathrm{O}$ desenvolvimento das Ciências Sociais no México, porém, teve uma singularidade importante por seu pioneirismo nas áreas de arqueologia/antropologia e história. Com a riqueza de seus sítios pré-colombianos, o Estado mexicano fundou, em 1917, o Instituto de Arqueologia, o mais antigo da América Latina, e, em 1939, o Instituto Nacional de Antropologia e História (INAH). As ciências sociais do México têm, pois, sua origem na história e na antropologia, cujo desenvolvimento se associou aos processos sociais do país, formando a matriz que, com o tempo, vai originar a sociologia e a ciência política (Reyna, 2007).
} 
Na Argentina, a primeira cátedra de sociologia foi estabelecida na Faculdade de Filosofia e Letras da Universidade de Buenos Aires (UBA), em 1898, ocupada por Ernesto Quesada entre 1904-1924. Na Universidade Nacional de Córdoba, fundou-se a segunda cátedra, em 1907, por iniciativa de Isidoro Ruiz Moreno; mas será criada ainda uma segunda cátedra na UBA (1908), na Faculdade de Direito, por Juan Agostín García. Enfim, nas Universidades Nacionais de La Plata (1909) e do Litoral (1914) foram também instituídas novas cátedras sob a direção de Agostín Álvarez e José Oliva, respectivamente. Esse primeiro processo de institucionalização concluiu-se em 1940, com a criação do Instituto de Sociologia da Faculdade de Filosofia e Letras da UBA, embora houvessem sido criadas cerca de cinquenta cátedras de sociologia até essa data. Apesar desses avanços em faculdades argentinas adicionadas às chilenas, há que reconhecer que a implantação institucional universitária da sociologia nesses dois países teve o atraso de uma década em comparação com o México, estabelecendo-se primeiro na Argentina e depois no Chile.

Na Argentina, houve o paradoxo de que o impulso inicial de desenvolvimento das ciências sociais aconteceu em um contexto de esgotamento do modelo de substituição de importações, num quadro em que a "revolução libertadora" que derrubou Juan Perón do governo (1955) possibilitou que a Universidade de Buenos Aires gozasse de uma grande autonomia, permitindo que, na época do reitorado do historiador José Luís Romero, fosse implantada a carreira de sociologia por Gino Germani, em 195544.

\footnotetext{
${ }^{44}$ Dois importantes centros privados de pesquisa são da mesma época: o Instituto de Desarrollo Económico (1958) e o Centro de Sociología Comparada (1963), assim como a eles estavam associadas duas revistas especializadas: Desarrollo Económico (1958) e a Revista Latinoamericana de Ciencias Sociales (1965), que reuniram em seus conselhos editoriais destacados cientistas sociais da região. Tiveram também grande importância para a legitimação das ciências sociais na Argentina duas editoras: a Paidós, com sua Biblioteca de Psicologia Social e Sociologia, e a Eudeba, vinculada à UBA.
} 
A resistência contra a sociologia no âmbito das universidades foi considerável na Argentina. Com o golpe militar que destituiu o presidente Hipólito Yrigoyen do terceiro governo do Partido Radical, em setembro de 1930, intelectuais, professores e estudantes, perseguidos e presos, tiveram de buscar outras alternativas institucionais. Nessa difícil conjuntura, em 1931, Roberto F. Giusti, Anibal Ponce, Carlos Ibargurem, Alejandro Korn, Narciso C. Laclau e Luis Reissig criaram o Colegio Libre de Estudios Superiores (CLES), em Buenos Aires. Reunindo professores e estudantes de orientação liberal e socialista, interessados no que denominaram, de forma simulada, de "cultura superior", associando-se também à "intelectualidade socialista" da Universidad Popular Alejandro Korn e da Escuela de Estudios Sociales de Juan B. Justo, realizavam cursos por meio de "cátedras livres" para discutir os problemas nacionais. Foi no CLES que Gino Germani iniciou-se em pesquisas empíricas sociológicas e no Censo argentino (ver Neiburg, 1998).

O Instituto de Sociología Argentina foi criado em 1927 na Facultad de Filosofía y Letras da UBA, mas somente na década de 1940, quando o historiador-sociólogo Ricardo Levene ${ }^{45}$ passou a dirigir o referido instituto, ele atingiu um novo patamar. Além de fundar a primeira revista - Boletín do Instituto de Sociología - e trazer para sua equipe ${ }^{46}$ o jovem promissor Gino Germani, promoveu pesquisas, cursos e conferências (ver Levene, 1947). Seu sucessor, Alfredo Poviña, tornou-se catedrático de sociologia em 1948, com significativa trajetória institucional: “[...] foi membro e presidente da Academia Nacional de Derecho y Ciencias Sociales de Córdoba

\footnotetext{
${ }^{45}$ R. Levene nasceu em Buenos Aires, em 1885, e com formação em história, direito e sociologia, foi titular da cátedra de sociologia desde 1918. A partir de 1940, assumiu a direção do Instituto de Sociologia da UBA. Obras principais: Las origines de la democracia argentina (1911), Ensayo histórico sobre la Revolución de Mayo y Mariano Moreno (1921), Historia de la Provincia de Buenos Aires y formación de su Pueblo (1941-1942), Las ideas históricas de Mitre (1948), El genio político de San Martin (1950) e História das Américas (1959), cuja edição brasileira foi dirigida por Pedro Calmon (Leven; Calmon, 1959).

${ }^{46}$ Em sua equipe, além de jovens argentinos com vocação sociológica, foram convidados alguns nomes de prestígio internacional: José Medina Echavarría e Mendieta y Núñez (México), e Gilberto Freyre (Brasil).
} 
e foi fundador da Academia Argentina de Sociología e da Associación Latinoamericana de Sociología (ALAS), desempenhando-se como primeiro presidente, entre 1951 e 1954" (Vitullo, 2013, p. 15) ${ }^{47}$.

Em países como Brasil, Uruguai e Chile, a sociologia emergiu em sociedades em um contexto de continuidade democrática, sem excluir crescentes tensões sociais e políticas produzidas pela crise do modelo "agrário-exportador" e com crescente mobilização social produzida pela adoção do modelo de "substituição de exportações". A disputa entre projetos de desenvolvimento marcou os caminhos da sociologia nesses países, embora num marco de maior liberdade política.

No Brasil, no final do séc. XIX, depois de um longo período de hegemonia dos bacharéis em direito - formados primeiro na Faculdade de Direito de Coimbra (ver Carvalho, 1980; 1988) e, depois da independência, nas Faculdades de Direto de Olinda/Recife (ver Chacon, 2008) e de São Paulo (ver Adorno, 1988) - foi emergindo uma geração de intelectuais "ensaístas": desde a geração de $1870^{48}$, na qual estava Joaquim Nabuco, geração que tomou posições coletivas na luta abolicionista em nome de uma liderança moral da nação; até o grupo dos "ensaístas reformadores", propulsores de uma "ideologia do Estado" do período entre as duas guerras mundiais, como Alberto Torres e Oliveira Viana (ver Lamounier, 1977).

O processo de institucionalização da sociologia foi tardio no Brasil em relação ao México e à Argentina - embora, em 1933, a disciplina tivesse sido incluída, por influência do Apostolado Positivista no Brasil, no currículo da Escola Militar no início da República e, mais tarde, nas

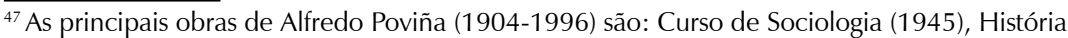
de la Sociología latinoamericana (1941) e Diccionario de Sociologia através de los sociólogos Tomos I y II (1976).

${ }^{48}$ Os filhos da nova burguesia urbana ingressaram nos centros de educação superior e assumiram o desafio de construir uma nação através do Estado; a sociologia inspirará assim uma série de obras relacionadas com a reforma pedagógica do ministro Botelho de Magalhães - militar que introduziu o ensino de sociologia na escola militar. Durante o período de 1920-1945, por fim, a derrota final dos "bacharéis" permitiu a expansão de um tipo de ciências sociais avant la lettre sob a forma de ensaios que abriu caminho a uma institucionalização plena (ver Alonso, 2002).
} 
Escolas Normais, em que foram criadas cátedras de sociologia (19241925): “[...] enquanto disciplina auxiliar da pedagogia dentro do esforço democratizante do movimento reformista pedagógico [...] que tem sua expressão maior no movimento da Escola Nova" (Liedke Filho, 2005 p. $380)^{49}$. Na realidade, o processo brasileiro de institucionalização da sociologia, em nível superior, foi iniciado no Estado de São Paulo, entre 1933 e 1934. Foi uma construção institucional, como resposta da elite paulista diante de duas derrotas: a primeira, provocada pela Revolução Liberal de 1930, com a ascensão de Getúlio Vargas ao poder; a segunda, ocorrida em 1932, quando da Revolução Constitucionalista de São Paulo ${ }^{50}$.

O processo institucional da sociologia resultou da criação, em 1933, da Escola Livre de Sociologia e Política de São Paulo (ver Limongi, 1989), que tinha por objetivo, como explicitado no Manifesto da Fundação da Escola, suprir a falta de "[...] uma elite numerosa e organizada, instruída sob métodos científicos, a par das instituições e conquistas do mundo civilizado, capaz de compreender antes de agir o meio social em que

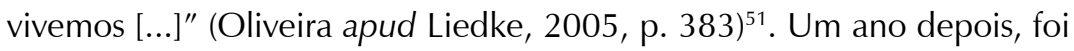
a criação da Seção de Sociologia e Política da Faculdade de Ciências e Letras, por ocasião da fundação, em 1934, da Universidade de São Paulo (USP), que, no Curso de Ciências Sociais da Faculdade de Filosofia, Ciências e Letras, instituiu a disciplina de sociologia. Seu primeiro catedrático foi um professor da Missão Francesa ${ }^{52}$, Roger Bastide. Essa cátedra de socio-

\footnotetext{
${ }^{49}$ Nesse momento, ocorreu a proliferação de publicações como manuais e coletâneas para o ensino de sociologia, os quais procuravam divulgar as ideias de cientistas sociais europeus e norte-americanos renomados, tais como Durkheim e Dewey.

${ }^{50}$ Para Florestan Fernandes: "[...] a USP e a ELSP são mecanismos de frações das classes dirigentes para conservar a hegemonia de São Paulo. Nós tentamos legitimar um domínio próprio de autonomia intelectual em nome da ciência e da solução racional dos problemas sociais" (1977, p. 14). ${ }^{51} \mathrm{Na}$ ELSP, "[...] sob a influência da Escola de Chicago, representada pelo nome de Donald Pierson, foi realizada uma série de estudos de comunidade a qual pode ser entendida como um primeiro programa de pesquisa nas ciências sociais brasileiras" (Liedke Filho, 2005, p. 383). ${ }^{52}$ Já na década de 1940, surgem os primeiros cursos de pós-graduação na área: na USP, mestrado e doutorado em antropologia, ciência política e sociologia; e na Universidade do Brasil e na ELSP, mestrado e doutorado em ciências sociais.
} 
logia da USP, posteriormente, foi assumida por Florestan Fernandes ${ }^{53}$. Na verdade, foi na década de 1950 que se iniciou a efetiva institucionalização da disciplina no ensino e pesquisa na USP, em torno da cátedra de Sociologia I, cognominada de "escola paulista de sociologia" (ver Arruda, 1989).

No Rio de Janeiro, essa institucionalização foi mais tardia e diversificada, em decorrência do fechamento, pelo Ministério de Educação, da Universidade do Distrito Federal (UDF), concebida e instituída por Anísio Teixeira, em 1935. Além disso, a nova Faculdade de Filosofia da Universidade do Brasil ficou controlada por professores e líderes católicos ligados ao Centro Dom Vital e à revista $A$ Ordem, fundada por Jackson Figueiredo e dirigida por Alceu Amoroso Lima, que recrutou outra Missão Francesa com orientação oposta à da USP ${ }^{54}$. Nessa dispersão, foram criadas outras instituições com perspectivas interdisciplinares. A primeira delas foi o Instituto Brasileiro de Economia, Sociologia e Política (1953), posteriormente reconvertido no Instituto Superior de Estudos Brasileiros (1955), laboratório da doutrina nacional-desenvolvimentista (Toledo, 1977). Na mesma década, foram criados o Instituto de Ciências Sociais da Universidade do Brasil, fundado por Evaristo Morais Filho, Luiz de Aguiar Costa Pinto e Victor Nunes Leal (ver Almeida, 1989), e o Curso de Sociologia e Política na PUC- RJ, pelo jesuíta Fernando Bastos D'Ávila, ambos em $1958^{55}$.

Fora do eixo São Paulo-Rio de Janeiro, foi fundado, em 1949, em Pernambuco, o Instituto Joaquim Nabuco, por Gilberto Freyre, e na Bahia desenvolveram-se importantes pesquisas sobre relações raciais no Brasil através de acordo internacional entre a Secretaria de Educação da Bahia

\footnotetext{
${ }^{53}$ Ver Fernandes, 1978.

${ }^{54}$ A missão francesa da Faculdade Nacional de Filosofia da Universidade do Brasil foi recrutada, principalmente, entre professores originários de Lyon, cidade de forte tradição católica, destacando-se, entre os professores, Jacques Lambert, autor de dois livros de referência: Os Dois Brasis (1970) e Amérique Latine (1968).

${ }^{55}$ No mesmo ano, foram instituídos, por jesuítas, cursos semelhantes na Argentina e no Chile (Quadro 1).
} 
(Anísio Teixeira) e a Universidade de Colúmbia (Charles Wagley), com o patrocínio da UNESCO e a participação de Thales de Azevedo (1996) pela Universidade da Bahia (Maio, 1997). A essas pesquisas associaram-se professores da USP (Roger Bastide e Florestan Fernandes) e do Rio de Janeiro (Costa Pinto e Guerreiro Ramos). Em Minas Gerais, a Faculdade de Ciências Econômicas, com a liderança do sociólogo Júlio Barbosa, implantou um curso interdisciplinar de sociologia, economia e administração pública, com um primeiro sistema de bolsas de estudos para os meIhores alunos de graduação, no qual se formaria uma importante geração de cientistas sociais ${ }^{56}$. No Rio Grande do Sul, foi criado, no final da década de 1950, o Curso de Ciências Sociais na Universidade Federal do Rio Grande do Sul, com forte influência de professores católicos conservadores, entre eles Laudelino Medeiros, catedrático de sociologia (Monteiro, 2006). A partir da década de 1970, essa hegemonia foi sendo superada por um duplo movimento: por um lado, pelo surgimento de outras lideranças acadêmicas e uma nova geração de professores com formação pós-graduada em sociologia; por outro, pelo processo de desenvolvimento acadêmico da ciência política e da antropologia e a construção institucional compartilhada do Programa de Mestrado de Antropologia, Política e Sociologia, base dos futuros doutorados.

No Uruguai, a primeira cátedra de sociologia foi instalada na Faculdade de Direito (1913), com a especificidade de ter sido instituída por via parlamentar para satisfazer os requisitos para criação de cátedras universitárias e referendada por decreto presidencial. Há bastante consenso na literatura ao reconhecer que, somente com a criação do Instituto de Ciencias Sociales, na Faculdade de Direito (1958), nasceu o embrião de institucionalização universitária da sociologia. Neste, não só se reúnem os dois professores "titulares" da faculdade, Isaac Ganón e Aldo Solari (am-

\footnotetext{
${ }^{56}$ Sobre a Faculdade de Ciências Econômicas de Minas Gerais e a expressão "neo-mineiros" ou "novos mineiros", ver Arruda, 1989.
} 
bos advogados e vinculados à maçonaria e ao partido Colorado), como também boa parte dos membros do ICS são originalmente advogados e sociólogos autodidatas. Na metade dos anos 1960, incorporaram-se, como "ajudantes", alguns novos sociólogos formados no exterior. Nada comparável ainda com o dinamismo institucional e profissional que se está produzindo contemporaneamente em Buenos Aires, São Paulo e, inclusive, em Santiago ${ }^{57}$.

No Chile, segundo Garretón, o primeiro período de institucionalização da sociologia (1950-1973) precedeu a um segundo momento (19731989) que coincidiu com a ditadura militar, o que implicou uma "[...] transição da 'sociologia de cátedra' e de tipo ensaísta a uma sociologia científica empírica [...]" (2007, p. 172). E acrescenta:

[...] a transição entre esses estilos sociológicos esteve associada aos processos de mudança que marcaram a década de 1940 [...] o triunfo da Frente Popular em 1938 e a mudança no modelo de desenvolvimento, industrialização com substituições de importações [...]. (Garretón, 2007, p. 173)

Na realidade, esse processo fundacional das ciências sociais associouse às transformações sociopolíticas, culturais e institucionais e ao papel preponderante do Estado como motor do desenvolvimento e de um efetivo sistema partidário (Garretón, 2007). A fase da "sociologia de cátedra" ou do "ensaísmo sociológico", comparada com a Argentina e o Brasil, foi menos relevante para a construção da sociologia. As primeiras gerações de sociólogos profissionais não se consideravam herdeiros desses precursores, como nos outros países. Havia uma tradição disciplinar mais forte na Faculdade de Economia, mas a institucionalização da "sociologia científica" se iniciou

\footnotetext{
${ }^{57}$ Cabe registrar que é nesse novo espaço que se promovem: o V Congresso de ALAS realizado em Montevidéu, a parte uruguaia da pesquisa comparativa sobre Estratificação e Mobilidade no Cone Sul (1959). E “ [...] foi a partir daí que se estimulou a postulação de estudantes para o mestrado na FLACSO e Chile, final decisivo para superar o já mencionado atraso de institucionalização da sociologia no Uruguai" (De Sierra, 2007, p. 232).
} 
na Faculdade de Filosofia e Educação, com Eduardo Hamuy, após seu retorno de formação pós-graduada nos Estados Unidos, quando assumiu o Instituto de Sociologia (1952). Este substituiu o antigo Centro de Pesquisas Sociológicas (1946). Mais tarde, os sociólogos de cátedra retornaram ao Instituto de Sociologia, em 1962, e a sociologia, como disciplina nas universidades, reapareceu somente na década de 1960. A Universidade Católica do Chile criou, em 1958, a Escola de Sociologia.

$\mathrm{Na}$ fase de 1948 a 1967 houve tempos diferenciados no processo de institucionalização da sociologia na América Latina (ver Quadro 1), onde se constata que a dinâmica de sua implantação em diferentes países se deu associada à circulação internacional de professores e alunos da região, com criação de instituições internacionais. Nesta fase das Ciências Sociais, não havia ainda cursos de pós-graduação em sociologia, e esse processo de intercâmbio entre os países latino-americanos representou o início de uma circulação transnacional na América Latina de economistas políticos e sociólogos, ambas as disciplinas se reconhecendo como integrantes das ciências sociais. Nesse contexto, será analisada, a seguir, a importância que teve, para a sociologia latino-americana, a presença de organismos internacionais: a Comisión Económica para América Latina (CEPAL) e a Facultad Latinoamericana de Ciencias Sociales (FLACSO), sediados em Santiago do Chile, e o Consejo Latinoamericano de Ciencias Sociales (CLACSO), em Buenos Aires.

\section{FLACSO/CLACSO e a estratégia internacional da sociologia}

A presença de organismos internacionais atuando no campo das ciências sociais teve um papel estratégico no perfil da reprodução da sociologia na América Latina, configurando uma "disciplinarização" internacionalizada e estabelecendo uma efetiva circulação internacional de 
professores e alunos ${ }^{58}$ - o que não ocorreu no processo de invenção da sociologia na Europa e nos Estados Unidos.

\subsection{A FLACSO}

A FLACSO foi criada como uma instituição internacional e intergovernamental de caráter regional e autônomo. Em 1956, a Conferência Geral da UNESCO aprovou o apoio aos países da América Latina para a criação de uma faculdade de ciências sociais. Os governos do Chile e do Brasil convocaram uma reunião dos países da região, no Rio de Janeiro, em abril de 1957, em que ficou deliberado que a FLACSO/Chile seria sediada em Santiago, onde se realizariam as atividades de ensino na Escuela Latinoamericana de Sociología (ELAS) e, no Rio de Janeiro, instalar-se-ia a FLACSO/Brasil, com a criação do Centro Latino-Americano de Ciências Sociais (CLAPCS) para pesquisas, com biblioteca especializada em ciências sociais e a revista América Latina, cujo primeiro diretor foi o sociólogo Luiz de Aguiar Costa Pinto. As duas sedes seriam coordenadas por um único comitê diretivo internacional, do qual fizeram parte um grupo de reconhecidos sociólogos representativos da região: Gino Germani (Argentina), Orlando Carvalho (Brasil), Eduardo Hamuy (Chile), José Rafael Arboleda (Colômbia), Lucio Mendieta y Núñez (México), Oscar Chaves Esquivel (Costa Rica), Isaac Ganón (Uruguai) e José Luis Salcedo-Bastardo (Venezuela).

A FLACSO foi concebida com o objetivo de promover o ensino, a pesquisa e a cooperação técnico-científica em ciências sociais em todo o subcontinente. Após duas conferências regionais e uma mundial, foram estabelecidas as recomendações de que se promovesse a cooperação entre os governos e as instituições interessadas em formar especialistas em sociologia em nível de pós-graduação. De fato, avaliou-se, nessas conferências, que seria desejável que cada país realizasse, dentro de suas

${ }^{58}$ Este subcapítulo em torno do papel dos organismos internacionais contou com a colaboração de Rosemeri Feijó, minha orientanda de doutorado no PPG em Políticas Públicas/UFRGS. 
universidades e instituições especializadas, a criação de programas de formação de pessoal em nível de graduação. A escassez de financiamento e de recursos humanos disponíveis não permitia ainda a criação de centros nacionais de pós-graduação.

Quando a FLACSO foi fundada, a Comisión Económica para la América Latina (CEPAL/ 1948), sediada também em Santiago, estava no auge de suas atividades de apoio à industrialização dos países da região, reunindo economistas políticos (Raul Prebish, Celso Furtado e Jorge Ahumada) e sociólogos do desenvolvimento (José Medina Echavarría, Fernando Henrique Cardoso e Enzo Faletto).

O papel da FLACSO foi decisivo para estabelecer a primeira circulação internacional de estudantes das ciências sociais. A geração dos novos sociólogos, além da formação pós-graduada através do ensino e na pesquisa (antes da implantação dos mestrados e doutorados na região), teve uma primeira experiência de estudo e pesquisa compartilhados. O corpo docente da Escuela Latinoamericana de Sociología (ELAS) era integrado por um grupo qualificado de professores permanentes: José Medina Echavarría (Espanha), Peter R. Heintz (Suíça), Gino Germani (Argentina), Gláucio Dillon Soares (Brasil), Johan Galtung (Noruega), Lucien Brams (França), entre outros; e professores visitantes: Alain Touraine e Edgar Morin (França), Fernando Henrique Cardoso (Brasil) e Stanislav Andreski (Polônia). Essa intensa e pioneira convivência acadêmica na ELAS permitiu o estabelecimento de laços importantes para uma institucionalização internacionalizada da sociologia, sem romper e até aprofundando as tradições nacionais, mas sobretudo contribuindo para uma expansão qualificada da disciplina no continente.

Seu padrão de atuação permite constatar seu papel na institucionalização internacionalizada da sociologia na América Latina, porque houve, efetivamente, nesse período, uma "circulação internacional" de alunos oriundos de diferentes países da América Latina, com a participação de 
professores recrutados em países europeus, onde a disciplina já estava consolidada. Os autores pioneiros formam uma "geração intermediária", que assume a tarefa de difundir e implantar o projeto renovador, desprezando os sociólogos de cátedra. Os sociólogos José Medina Echavarría e Gino Germani tiveram grande influência na sociologia latino-americana nas décadas de 1950 e 1960, respectivamente. Geraram uma renovação, combinando a tradição mais empírica, de influência norte-americana, com a "grande teoria" do velho continente.

A FLACSO, portanto, surgiu da vontade comum dos países latino-americanos que trabalharam de forma articulada para dispor de um centro que não competisse com as atividades em curso nas universidades nacionais, mas que deveria servir a todas elas em seu propósito de formar sociólogos qualificados. De fato, ela foi essencialmente um instituto de pós-graduação, com alunos bolsistas formados na graduação nos diversos países da América Latina, propondo-se a diminuir, na medida do possível, o desequilíbrio inter-regional ${ }^{59}$. Além das relações que mantinha com as universidades da região, a FLACSO se preocupava com desenvolvimento de intercâmbios com alguns centros universitários europeus e norte-americanos para criar cooperação científica internacional. Esta iniciativa viabilizou um acordo de cooperação com a École pratique des hautes études en sciences sociales ${ }^{60}$.

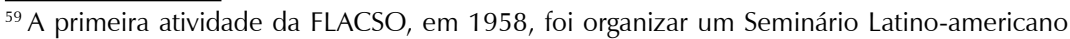
sobre Metodologia do Ensino e da Pesquisa das Ciências Sociais, o que colocou a instituição na ponta das Ciências Sociais da região.

${ }^{60} \mathrm{O}$ acordo previa a vinda de especialistas franceses para ensinar ou pesquisar na FLACSO sobre o desenvolvimento econômico e social latino-americano, em especial sobre os problemas de adaptação às mudanças técnicas e sobre os efeitos psicológicos, econômicos, demográficos e sociais da industrialização e da urbanização. Também eram previstas bolsas para os melhores alunos de cada turma da FLACSO ou de outras instituições latino-americanas indicadas por esta.
} 
As atividades de ensino da FLACSO iniciaram-se com 20 estudantes provenientes de Argentina, Brasil, Colômbia, Costa Rica, Chile, Equador, México, Panamá, Peru e Uruguai. A partir dessa primeira edição, frequentaram os estudos superiores na Facultad de Sociología, em cinco turmas com dois anos de duração, 132 jovens latino-americanos. Embora não haja muitas informações sobre as primeiras delas, a seleção da terceira turma foi feita pelo professor francês Lucien Brams, que viajou pelos países da América Latina convocando alunos para formar o novo grupo. A seleção de alunos brasileiros resultou no recrutamento de um grupo de recém-graduados na Faculdade de Ciências Econômicas (FACE) ${ }^{61}$ de Minas Gerais ${ }^{62}$ : Fábio Wanderly Reis, Antônio Octávio Cintra, Simon Schwartzman, Suzana Prates e José Maria de Carvalho. O Brasil esteve presente em todas as edições, formando intelectuais importantes e a geração que impulsionou as ciências sociais na América Latina na década de 1960. Essa participação de brasileiros nas edições da FLACSO sugere a importância desta instituição na dinâmica da sociologia brasileira. No total, foram formadas dez turmas da FLACSO, das quais participaram docentes latino-americanos e estrangeiros com alunos originários de diversos países da América Latina, e, em número menor, dos Estados Unidos e Europa.

No início do século XX, os países da América Latina mantinham uma relação maior com a Europa, mas já nos anos 1950 ela passou a ser mais intensa com os Estados Unidos. Essa formação pós-graduada no exterior, os intercâmbios e os eventos internacionais davam legitimidade acadêmica aos intelectuais latino-americanos, ao retornarem de sua formação no velho continente e na América do Norte. No entanto, essa prática se

\footnotetext{
${ }^{61} \mathrm{O}$ curso de Sociologia e Política e Administração Pública da Faculdade de Ciências Econômicas era, originalmente, de uma faculdade privada (FACE) e posteriormente foi transferido para a UFMG.

${ }^{62}$ Além dos brasileiros que foram recrutados para a terceira turma, participaram de outras edições Vilmar Faria, Alaor Passos e José Armando de Souza, Maria Hermínia Tavares de Almeida e Lourdes Sola, entre outros.
} 
modificou com a presença da FLACSO, que se tornou um experimento exitoso de formação de nível internacional na América Latina, provando que era possível formar sucessivas gerações de sociólogos latino-americanos com boa qualificação acadêmica na própria região, preocupadas com as problemáticas regionais, sem perder a perspectiva mundial. Essa iniciativa produziu uma revolução na formação, provocando, de uma maneira natural, uma mudança na estratégia de pesquisas e na relevância de seus temas. No que se refere à influência dos diferentes países com maior tradição de pesquisa e reflexão, o predomínio (apesar de a maioria dos professores ser constituída de europeus) era da orientação norte-americana, com grande atenção para a produção sociológica dos Estados Unidos e preocupação com a articulação entre o trabalho teórico e a referência empírica (Delich, 1979).

A fundação da FLACSO deve ser situada no contexto das ciências sociais latino-americanas da década de 1950 para se compreender o papel estratégico que tiveram organismos internacionais (CEPAL) na institucionalização da sociologia com esse perfil transnacional, contribuindo para a sua consolidação a partir das décadas de 1960-1970. Duas décadas mais tarde, em 1967, a organização do Consejo Latinoamericano de Ciencias Sociales (CLACSO), na Argentina, completou esse processo.

\subsection{O CLACSO}

Em 1967, foi criado, por iniciativa de um grupo cientistas sociais argentinos, o Consejo Latinoamericano de Ciencias Sociales (CLACSO), com sede em Buenos Aires. À frente da comissão organizadora, esteve o economista político argentino, Aldo Ferrer, seu primeiro secretário-executivo. Tratava-se de uma associação internacional, de caráter não governamental e reconhecida como organismo consultivo da UNESCO, que tinha como finalidade reunir institutos e centros de pesquisa latino-americanos em ciências sociais. O CLACSO constitui-se como um projeto interinsti- 
tucional autônomo, sem o patrocínio externo de organismo internacional (como foi o caso da CEPAL e da FLACSO), com o objetivo de estimular e aprofundar o intercâmbio e a cooperação entre centros distribuídos no continente latino-americano e caribenho.

Sua estrutura organizativa é constituída por uma Assembleia integrada por representantes dos centros filiados; por uma Secretaria Executiva coordenando o Comitê Diretivo, composto por um grupo de representantes eleitos ${ }^{63}$ dentre os centros de maior prestígio dos países da região. A articulação entre ambos conduz a atividades de pesquisa com interação permanente entre os centros associados, por meio de reuniões periódicas realizadas, de forma descentralizada, em suas sedes nacionais. O CLACSO tem como finalidade básica contribuir para o desenvolvimento dos centros associados, buscando uma melhor cooperação entre eles, através de pesquisas compartilhadas e grupos de trabalho temáticos (GTs).

Em seu pronunciamento inaugural, o primeiro secretário-geral do CLACSO, Aldo Ferrer, definiu a vocação do novo Conselho: "[...] quiero decir que el organismo es solo un instrumento al servicio de los institutos y centros nacionales y de ninguna manera un órgano sobreimpuesto a los mismos" (CLACSO, 1968). Os comitês diretivos da FLACSO e do CLACSO eram formados por intelectuais de renome regional e mundial e se poderia pensar que haveria uma concorrência entre as duas instituições. Isso não ocorreu; ambos tinham status jurídico diferente e, enquanto o CLACSO coordenava atividades de pesquisa, a FLACSO se dedicava ao ensino e à pesquisa (Beigel, 2009).

O CLACSO teve um papel fundamental para essa nova etapa de institucionalização das ciências sociais na América Latina e Caribe, inclusive, coordenando a implantação de cursos de pós-graduação (mes-

${ }^{63} \mathrm{O}$ Comitê Diretivo, com expansão do CLACSO, teve 18 membros eleitos pela Assembleia Geral por período de quatro anos, composto de especialistas latino-americanos de reconhecido valor científico. 
trado) em países em que havia formação de quadros insuficiente para o ensino e a pesquisa ${ }^{64}$. O projeto de pós-graduação mais ambicioso foi o que formou uma comissão internacional de reconhecidos cientistas sociais - argentinos, brasileiros e chilenos - para criar, com uma estrutura transnacional, um primeiro programa de doutorado transnacional em ciências sociais com sedes em Buenos Aires, Rio de Janeiro e Santiago do Chile. Esse importante programa interinstitucional avançou bastante na sua elaboração compartilhada, mas acabou sendo, lamentavelmente, abortado pelos golpes militares que ocorreram nos três países. Vale registar que, durante as ditaduras do Cone Sul, o CLACSO concedeu apoio financeiro aos centros perseguidos, especialmente os do Chile, com recursos oriundos de fundações internacionais europeias ${ }^{65}$. Outra contribuição relevante do Conselho foi a implantação, ao lado do Boletim Informativo, das revistas David e Colias e Crítica \& Utopía, a organização da Biblioteca de Ciências Sociais da instituição, que reúne um imenso acervo de livros produzidos pelos GTs, por pesquisas interinstitucionais e obras de autores individuais. Desde a sua criação, realizou esforços para consolidar a autonomia das ciências sociais na América Latina nos planos teórico e metodológico, atribuindo aos pesquisadores um fórum de discussão nos temas considerados prioritários para a problemática regional e, ao mesmo tempo, incorporando novas perspectivas analíticas (teórico-metodológicas), com ênfase em pesquisas interdisciplinares.

O exame da listagem dos primeiros integrantes do Comitê Diretivo do CLACSO permite avaliar a qualidade acadêmica e a representatividade institucional de seus membros. Estiveram presentes, desde sua fundação, cientistas sociais do primeiro grupo de centros que se asso-

\footnotetext{
${ }^{64}$ Como exemplo, temos o Curso Avançado Latino-americano em Sociologia Rural, que tinha um caráter itinerante e um prazo limitado de funcionamento.

${ }^{65}$ Esses financiamentos externos eram concedidos principalmente por fundações dos países nórdicos.
} 
ciaram à instituição. O Brasil teve três membros precursores: Hélio Jaguaribe (IEPS); Isaac Kerstenetzky (IBGE), do Rio de Janeiro; e Júlio Barbosa (Faculdade de Ciências Econômicas de Minas Gerais). A USP começa a integrar o Comitê num segundo momento, primeiro com o sociólogo Juarez Brandão Lopes, seguido por Fernando Henrique Cardoso. A Argentina e o Chile foram representados por nomes de grande prestígio: Gino Germani (UBA) e Raul Prebisch (CEPAL). O nome de Enrique Oteiza é emblemático, porque, além de ter sido diretor do primeiro centro argentino Torcuato di Tella, foi um dos mais atuantes dentre os secretários executivos do CLACSO, tornando-se um dos pilares da instituição. Do México, fizeram parte dois renomados representantes do Colegio de México: Rodolfo Stavenhagen e Victor Urquidi. Finalmente, Orlando Fals Borda e Luis Ratinoff, da Colômbia; Luis Lander, da Venezuela; José Matos Mar, do Peru; e Enrique Iglesias, do Uruguai ${ }^{66}$.

O CLACSO contou, desde sua fundação, com 35 centros associados, número que foi aumentando consideravelmente ao longo dos anos. Em 1979, existiam 80 centros de pesquisa, correspondendo a 17 países e, a partir dos anos 1980, associaram-se cerca de 150 centros. Atualmente, conta com um número expressivo de instituições associadas em um total de 41 países.

O CLACSO se mantém com financiamento de diferentes origens: a anualidade paga pelos institutos e centros filiados, financiamentos de organismos internacionais, fundações e instituições privadas e/ou governamentais e os próprios centros que integram o Conselho. As fontes são bem diversificadas e, geralmente, suas contribuições estão vinculadas ao financiamento de projetos de pesquisa interinstitucionais, dos grupos de

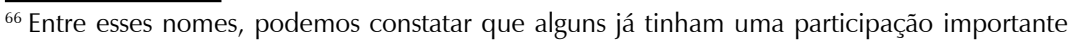
nas outras organizações latino-americanas: Raúl Prebisch, Diretor da CEPAL; Gino Germani na FLACSO e na fundação da Carreira de Sociologia na Universidade de Buenos Aires. 
trabalho (GTs), das atividades da Secretaria Executiva, das reuniões do Comitê Diretivo em diferentes países e de suas publicações institucionais.

Finalmente, caberia ressaltar a importância estratégica do CLACSO em seu papel de definir efetivamente políticas transnacionais para o desenvolvimento das ciências sociais na região, numa época em que os organismos estatais de fomento à pesquisa e à pós-graduação (ministérios de ciência e tecnologia e agências governamentais públicas estatais) eram ainda inexistentes. Essa liderança abrangente foi pesando menos na política concreta de pesquisa nos diferentes centros e países, hierarquizou-se a política editorial, a biblioteca virtual latino-americana e o estímulo a grupos de trabalho que, com o tempo, aumentaram muito em quantidade e passaram, em grande medida, a ser autofinanciados devido à redução dos fundos de apoio. A isto, agrega-se o fato de que o papel originário do CLACSO foi sendo compartilhado também pelo fortalecimento da ALAS; o desenvolvimento de associações nacionais e regionais, a redução significativa das contribuições financeiras das agências internacionais e a implantação, pelos governos da região, de organismos estatais em áreas de pesquisa em ciências sociais. Todos esses fatores contribuíram para que novas estratégias fossem praticadas, relativizando suas políticas institucionais pluralistas.

\section{Considerações finais}

A análise em perspectiva sobre as origens da "disciplinarização" e institucionalização da sociologia nos países centrais fundadores e o correspondente processo de reprodução na América Latina pretende oferecer aos leitores os eixos centrais, com olhares cruzados, as estratégias fundantes da nova disciplina. Busca mostrar, com seus avanços e recuos, como a sociologia conquistou seus espaços legítimos em contextos históricos radicalmente diferenciados no tempo e no espaço. 
Certamente, seria necessário um aprofundamento maior para avançar numa perspectiva comparativa entre esses dois processos diacrônicos. Numa primeira abordagem, pode-se observar que a reprodução da sociologia na América Latina se deu de forma menos conflitiva e, consequentemente, mais cooperativa do que nos países centrais. O Quadro 1, da institucionalização da sociologia na América Latina, em perspectiva, de 1887 a 1967, mostra uma diversificação na importação e sua implantação com perfis próprios nos diversos países. Entretanto, observa-se uma convergência na construção institucional mais consistente que nos países fundadores, na medida em que diferentes formas de internacionalização contribuíram para a circulação interinstitucional de alunos e professores, o intercâmbio para a formação acadêmica, para as pesquisas e eventos conjuntos. E, numa fase posterior, pela convivência intensa e dramática no exílio dos perseguidos políticos pelas ditaduras militares do Cone Sul. Na Europa, ao contrário, além das variantes nacionais na invenção da sociologia, o distanciamento e as disputas entre os fundadores revelaram-se mais intensos que no continente latino-americano, afetando uma cooperação aberta entre atores e instituições.

Hélgio Trindade é Professor emérito, pesquisador sênior do CNPq, ex-reitor da UFRGS e da UNILA, atualmente professor do Programa de Pós-graduação em Políticas Públicas da UFRGS. \helgiohtrindade@gmail.com 


\section{Referências}

1. ADORNO, Sérgio. Os Aprendizes do Poder. São Paulo: Paz Terra, 1988.

2. ALTAMIRANO, Carlos. Historia de los intelectuales en América Latina: los avatares de la "ciudad letrada" en el siglo XX. Buenos Aires: Katz, 2010.

3. AGRAMONTE, Roberto D. (Ed.). Mendieta y Nuñez y su magisterio sociológico. Cidade do México: Editorial Cultura, 1961.

4. ALMEIDA, Maria Hermínia T. Dilemas da Institucionalização das Ciências Sociais no Rio de Janeiro. In: MICELI, Sérgio (org.). História das ciências sociais no Brasil. São Paulo: Sumaré, 1989.

5. ALONSO, Ângela. Idéias em movimento: A Geração de 1870 na crise do Brasil-Império. Rio de Janeiro: Paz e Terra, 2002.

6. ARCINIEGA, Víctor Díaz. Historia de la Casa: Fondo de Cultura Económica (1934-1996). Cidade do México: Fondo de Cultura Económico, 1996.

7. ARRUDA, Maria Arminda do Nascimento. A Modernidade Possível: Cientistas e Ciências Sociais em Minas Gerais. In: MICELI, Sérgio. História das Ciências Sociais no Brasil. v.1. São Paulo: Vértice; IDESP, 1989.

8. BARNES, Harry Elmer. An introduction to the history of sociology. Chicago: University of Chicago Press, 1948.

9. BEIGEL, Fernanda. La FLACSO chilena y la regionalización de las ciencias sociales en América Latina (1957-1973). Revista Mexicana de Sociología, México, D.F., v. 2009, n. 2, p. 319-349, 2009.

10. BOUGLÉ, Celestin. Les sciences sociales en Allemagne: les méthodes actuelles. Paris: Alcan, 1896.

11. BOURDIEU, Pierre. Homo academicus. Paris: Éditions de Minuit, 1984.

12. BLANCO, Alejandro. La Asociación Latinoamericana de Sociología: una historia de sus primeros congresos. Sociologias, Porto Alegre, ano 7, n.14, p. 22-49, jul./dez. 2005.

13. BLANCO, Alejandro (Comp.); GERMANI, Gino. Gino Germani: La renovación intelectual de la sociología. Bernal: Universidad Nacional de Quilmes, 2006.

14. CARVALHO, José Murilo de. A construção da ordem. Rio de Janeiro: Campus, 1980

15. CARVALHO, José Murilo de. Teatro de sombras: a política nacional. Rio de Janeiro, Ed. Vértice, 1988. 
16. CHACON, Valmireh. A formação das Ciências Sociais no Brasil: Da Escola de Recife ao Código Civil. 2ª . ed. São Paulo: Unesp Ed./LGE Paralelo 15, 2008.

17. CHARLE, Christophe. Naissance des "intellectuels". Paris: Les Éditions de Minuit, 1990.

18. CHARLE, Christophe. La république des universitaires : 1870-1940. Paris: Seuil, 1994.

19. CHARLE, Christophe. Les intellectuels en Europe aux XIX siècle : essai d'histoire comparée. 2a. ed. Paris: Seuil, 2001.

20. CHARLE, Christophe; VERGER, Jacques. Histoire des universités: XIle-XXle siècle. Paris: PUF, 2012

21. CHAPOULIE, Jean-Michel. La tradition sociologique de Chicago (18921961). Paris: Seuil, 2001.

22. CLAPCS. As Ciências sociais na América Latina. São Paulo: Difusão Europeia do Livro, s/d.

23. CLACSO. Boletínes CLACSO. Buenos Aires, n. 5, ene./febr. 1968.

24. COMTE, Auguste. La classification des six sciences fondamentales. In: COMTE, Auguste. Cours de philosophie positive (1ère et 2ème leçons). Paris: Hachette, 1946. p. 88-100.

25. COMTE, Auguste. Système de politique positive ou Traité de Sociologie, instituant la religion de I'Humanité. t. 1-4. Paris: Carilian-Coeury et V. Dalmont, 1890.

26. CUIN, Charles Henri; GRESLE, François. Histoire de la sociologie: Avant 1918. Paris: La Découverte, 1996.

27. DELICH, Francisco. Las condiciones sociales de la democracia. Crítica \& Utopía. Revista Latinoamericana de ciencias sociales, Buenos Aires, n. 1, sept. 1979.

28. DE SIERRA, Gerónimo. Ciencias Sociales en Chile y Uruguay. In: TRINDADE, Hélgio (Coord.). Las ciencias sociales en América Latina: de los inicios de la sociología a la teoría de dependencia. Buenos Aires: Eudeba, 2013. p. 231-237.

29. DURAND, Jean-P.; WEIL, Robert. Sociologie contemporaine. Paris: Vigot, 2006.

30. ECHAVARRÍA, José Medina. Sociología: teoría y técnica. México: Fondo de Cultura Económica, 1941.

31. EUfRASIO, Mário A. A formação da escola sociológica de Chicago. Plural, São Paulo, v. 2, p. 37-60, 1. sem. 1995. 
32. FERNANDES, Florestan. A sociologia no Brasil. Petrópolis: Vozes, 1977.

33. FERNANDES, Florestan. A Condição de Sociólogo. São Paulo: HUCITEC, 1978.

34. FLEMING, Donald. Social Darwinism. In: SCHLESINGER Jr., Arthur; WHITE, Morton (Ed.). Paths to American Thought. Boston: Houghton Miffin, 1963. p. 123-146.

35. FOURIER, Charles. Le nouveau monde industriel et sociétaire. In: FOURIER, C. OEuvres complètes. v. 6. Paris: Anthropos, 1971.

36. FOURNIER, Marcel. Émile Durkheim (1858-1917). Paris: Fayard, 2007.

37. GARCIADIEGO, Javier. De la Casa al Colegio de México. In: LIDA, Clara E.; MATESANZ, José A.; VÁSQUEZ, Josefina Z. La Casa de España y el Colegio de México (Memoria, 1938-2000). México, D.F.: Colegio de México, 2000. p. 117123.

38. GERMANI, Ana Alejandra. Gino Germani: Del antifascismo a Sociología. Buenos Aires: Aguilar; Altea; Taurus; Alfaguara, 2004.

39. GERMANI, Gino. La Sociología en América Latina: problemas y perspectivas. Buenos Aires: Editorial Universitaria de Buenos Aires, 1964.

40. GUILLÉN, Jaime T. Dialéctica de la Imaginación: Pablo González Casanova - una biografía intelectual. México, D.F.: La Jornada Ediciones, 2014.

41. HAUSER, Henri. L'Enseignement des sciences sociales: Etat actuel de cet enseignement dans les divers pays du monde. Paris: Chevalier-Marescq, 1903.

42. HAYS, Samuel P. Response to industrialism (1885-1914). Chicago: University of Chicago Press, 1957.

43. KARADY, Victor. Durkheim, les sciences sociales et I'Université : bilan d'un semi-échec. Revue française de sociologie, ano 1976, n. XVII-2, p. 267-311.

44. LAMOUNIER, Bolívar. Ideologia do Estado. In: FAUSTO, Boris (Dir.). História Geral da Civilização Brasileira. O Brasil Republicano: sociedade e política (1930-1964). v. 10. t. 3. São Paulo, Difel, 1977. p. 343-374.

45. LEPENIES, Wolf. Les trois cultures: entre science et littérature I'avènement de la sociologie. Paris: Maison des sciences de l'homme, 1990.

46. LEVENE, Ricardo. La Cátedra y El Instituto de Sociología de la Facultad de Filosofía y Letras de Buenos Aires. Boletín del Instituto de Sociología. N. 5, marzo de 1947. 
47. LEVENE, Ricardo; CALMON, Pedro. História das Américas. (14 vols), 4aa ed. Rio de Janeiro, São Paulo, Porto Alegre: V.M. Jackson Inc., 1959.

48. LIDA, Clara E.; MATESANZ, José A.; VÁSQUEZ, Josefina Z.. La Casa de España y el Colegio de México (Memoria, 1938-2000). México, D.F.: Colegio de México, 2000.

49. LIEDKE FILHO, Enno D. A Sociologia no Brasil: história, teorias e desafios. Sociologias, Porto Alegre, n. 14, p. 376-437, jul./dez., 2005.

50. LIMONGI, Fenando. A Escola Livre de Sociologia e Política. In: MICELI, Sérgio (Org.). História das Ciências Sociais no Brasil. v. 1. São Paulo: Vértice; IDESP, 1989.

51. MAIO, Marcos C. A História do Projeto Unesco: Estudos Raciais e Ciências Sociais. Rio de Janeiro: IUPERJ, 1997.

52. MARX, Karl. Critique du droit politique hégélien. Trad. e introd. Albert Baraquin. Paris: Éditions sociales, 1975.

53. MARX, Karl. Misère de la philosophie. Paris: A. Franck; Bruxelles: C.G. Vogler, 1847.

54. MARX, Karl. Les luttes de classes en France (1848-1850). Paris: Éditions Sociales, 1948.

55. MARX, Karl. Le 18 Brumaire de Louis Bonaparte. Paris: Les Éditions Sociales, [1852] 1969.

56. MARX, Karl. Le Capital. t. 1-3. Paris: PUF, [1867]1993.

57. MICELI, Sérgio (Org.). História das Ciências Sociais no Brasil. v. 1. São Paulo: Vértice; IDESP, 1989.

58. MICELI, Sérgio (Org.). História das Ciências Sociais no Brasil. v. 2. São Paulo: IDESP, 1995.

59. MUCCHIELLI, Laurent. La découverte du social: Naissance de la sociologie en France (1870-1940). Paris: Éditions La Découverte, 1998.

60. MUCCHIELLI, Laurent. O nascimento da sociologia na universidade francesa (1880-1914). Revista Brasileira de História, São Paulo, v. 21, n. 4, p. 35-54, 2001.

61. NEIBURG, Federico. Los intelectuales y la invención del peronismo. Buenos Aires: Alianza, 1998.

62. PAPILLOUD, Christian. Introduction à la sociologie allemande. Paris: Liber, 2011. 
63. PETIT, Annie. A escola positivista: da sociologia à sociopolítica. In: TRINDADE, Helgio (Org.). O Positivismo: teoria e prática. Porto Alegre: UFRGS; Brasília: UNESCO, 2007. p. 33-62.

64. POVIÑA, Alfredo. Historia de la sociología en Latinoamérica. México, D.F.: Fondo de Cultura Económica, 1941.

65. REYNA, José Luis. A Institucionalização das Ciências Sociais no México. In: TRINDADE, Hélgio (Org.). As Ciências Sociais na América Latina em Perspectiva Comparada: 1930-2005. 2a․ ed. Porto Alegre: UFRGS; ANPOCS, 2007.

66. RINGER, Fritz K. O declínio dos Mandarins Alemães: A comunidade acadêmica alemã, 1890-1933. São Paulo: EDUSP, 2000.

67. SAINT-SIMON, C.-H. L'Industrie. In: SAINT-SIMON, Claude-Henri. OEuvres complètes. vols. 1-2. Paris: Anthropos, 1966.

68. SAINT-SIMON, C.-H. Catéchisme des Industriels. In: SAINT-SIMON, C.-H. OEuvres complètes. vols. 4-5. Paris: Anthropos, 1966.

69. SANTOS, José Vicente Tavares dos; BAUMGARTEN, Maíra. Editorial. Sociologias, Porto Alegre, v. 7, n. 14, pp.10-15, jul./dez. 2005a.

70. SANTOS, José Vicente T. dos; BAUMGARTEN, Maíra. Contribuições da Sociologia na América Latina à imaginação sociológica: análise crítica e compromisso social. Sociologias, v. 7, n. 14, pp. 178-243, jul./dez. 2005 b.

71. SinGARAVÉlOU, Pierre. Professer I'Empire: Les "sciences coloniales" en France sous la IIle République. Paris: Publications de la Sorbonne, 2011.

72. SPENCER, Herbert. Principes de Sociologie. v. 1-4. Paris : Felix Alcan Éditeur, 1910.

73. TOLEDO, Caio Navarro de. ISEB: Fábrica de Ideologias. São Paulo: Ática, 1977.

74. TOCQUEVILLE, Alexis. De la démocratie en Amérique I. Paris: Gallimard, 1992a [1835]. (Collection: Bibliothèque de la Pléiade).

75. TOCQUEVILLE, Alexis. De la démocratie en Amérique II. Paris: Gallimard, 1992b [1840]. (Collection: Bibliothèque de la Pléiade).

76. TRINDADE, Hélgio. Institucionalização e internacionalização das ciências sociais na América Latina em questão. In: ALMEIDA, Ana Maria F. et al. Circulação Internacional e formação intelectual das elites brasileiras. Campinas: UNICAMP, 2004. p. 144-167. 
77. TRINDADE, Hélgio. (Ed.). Social Sciences in Latin America/ Les sciences sociales en Amérique Latine (1930-2003). Social Science information sur les sciences sociales, London, v. 44, n. 2-3, p. 219-226, June/Sept. 2005.

78. TRINDADE, Hélgio (Org.). As Ciências Sociais na América Latina em perspectiva comparada: 1930-2005. 2. ed. Porto Alegre: UFRGS; ANPOCS, 2006.

79. TRINDADE, Hélgio (Coord.). Las Ciencias Sociales en América Latina en perspectiva comparada: 1930-2005. México, D.F.: Siglo XXI, 2007.

80. TRINDADE, Hélgio. Ciências Sociais no Brasil: diálogos com mestres e discípulos. Brasília, DF: Liber Livro; ANPOCS, 2012.

81. TRINDADE, Hélgio (Coord.) et al. Las ciencias sociales en América Latina: de los inicios de la teoría de la dependencia. Buenos Aires: Eudeba, 2013

82. VITULLO, Gabriel. Las Ciencias Sociales en Argentina. In: TRINDADE, Hélgio (Coord.). Ciencias Sociales en América Latina: de los inicios a la teoría de la dependencia. Buenos Aires: Eudeba, 2013. p.13-22.

83. WEBER, Marianne. Weber: uma biografia. Niterói: Casa Jorge Editorial, 2003. 84. WEISS, Raquel; BENTHIEN, Rafael F.; NEVES, Clarissa E.B. (Orgs.). Dossiê: 100 anos sem Durkheim, 100 anos com Durkheim. Sociologias, v. 19, n. 44, 2017

85. WORMS, René. Organisme et Société. Paris: V. Giard \& E. Brière, 1896.

Recebido: 09.10.2017

Aceite final: 31.10 .2017

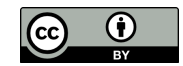

